\title{
Mooring Observations of Air-Sea Heat Fluxes in Two Subantarctic Mode Water Formation Regions ${ }^{\mathscr{O}}$
}

\author{
VERONICA TAMSITT \\ Hemisphere Oceans Research, CSIRO Oceans and Atmosphere, Hobart, Tasmania, Australia \\ IVANA CEROVEČKI \\ Scripps Institution of Oceanography, La Jolla, California \\ SIMON A. JOSEY \\ National Oceanography Centre, Southampton, United Kingdom \\ SARAH T. GILLE \\ Scripps Institution of Oceanography, La Jolla, California \\ ERIC SCHULZ \\ Bureau of Meteorology, Melbourne, Victoria, Australia
}

Climate Change Research Centre, University of New South Wales, Sydney, New South Wales, and Centre for Southern

(Manuscript received 29 August 2019, in final form 18 December 2019)

\begin{abstract}
Wintertime surface ocean heat loss is the key process driving the formation of Subantarctic Mode Water (SAMW), but there are few direct observations of heat fluxes, particularly during winter. The Ocean Observatories Initiative (OOI) Southern Ocean mooring in the southeast Pacific Ocean and the Southern Ocean Flux Station (SOFS) in the southeast Indian Ocean provide the first concurrent, multiyear time series of air-sea fluxes in the Southern Ocean from two key SAMW formation regions. In this work we compare drivers of wintertime heat loss and SAMW formation by comparing air-sea fluxes and mixed layers at these two mooring locations. A gridded Argo product and the ERA5 reanalysis product provide temporal and spatial context for the mooring observations. Turbulent ocean heat loss is on average 1.5 times larger in the southeast Indian (SOFS) than in the southeast Pacific (OOI), with stronger extreme heat flux events in the southeast Indian leading to larger cumulative winter ocean heat loss. Turbulent heat loss events in the southeast Indian (SOFS) occur in two atmospheric regimes (cold air from the south or dry air circulating via the north), while heat loss events in the southeast Pacific (OOI) occur in a single atmospheric regime (cold air from the south). On interannual time scales, wintertime anomalies in net heat flux and mixed layer depth (MLD) are often correlated at the two sites, particularly when wintertime MLDs are anomalously deep. This relationship is part of a larger basin-scale zonal dipole in heat flux and MLD anomalies present in both the Indian and Pacific basins, associated with anomalous meridional atmospheric circulation.
\end{abstract}

Supplemental information related to this paper is available at the Journals Online website: https://doi.org/10.1175/JCLI-D-190653.s1.

Corresponding author: V. Tamsitt, veronica.tamsitt@gmail.com

\section{Introduction}

The Southern Ocean has been identified as a key region for oceanic uptake and storage of anthropogenic carbon and heat (Sabine et al. 2004; Ito et al. 2010), and Subantarctic Mode Water (SAMW) formation and 


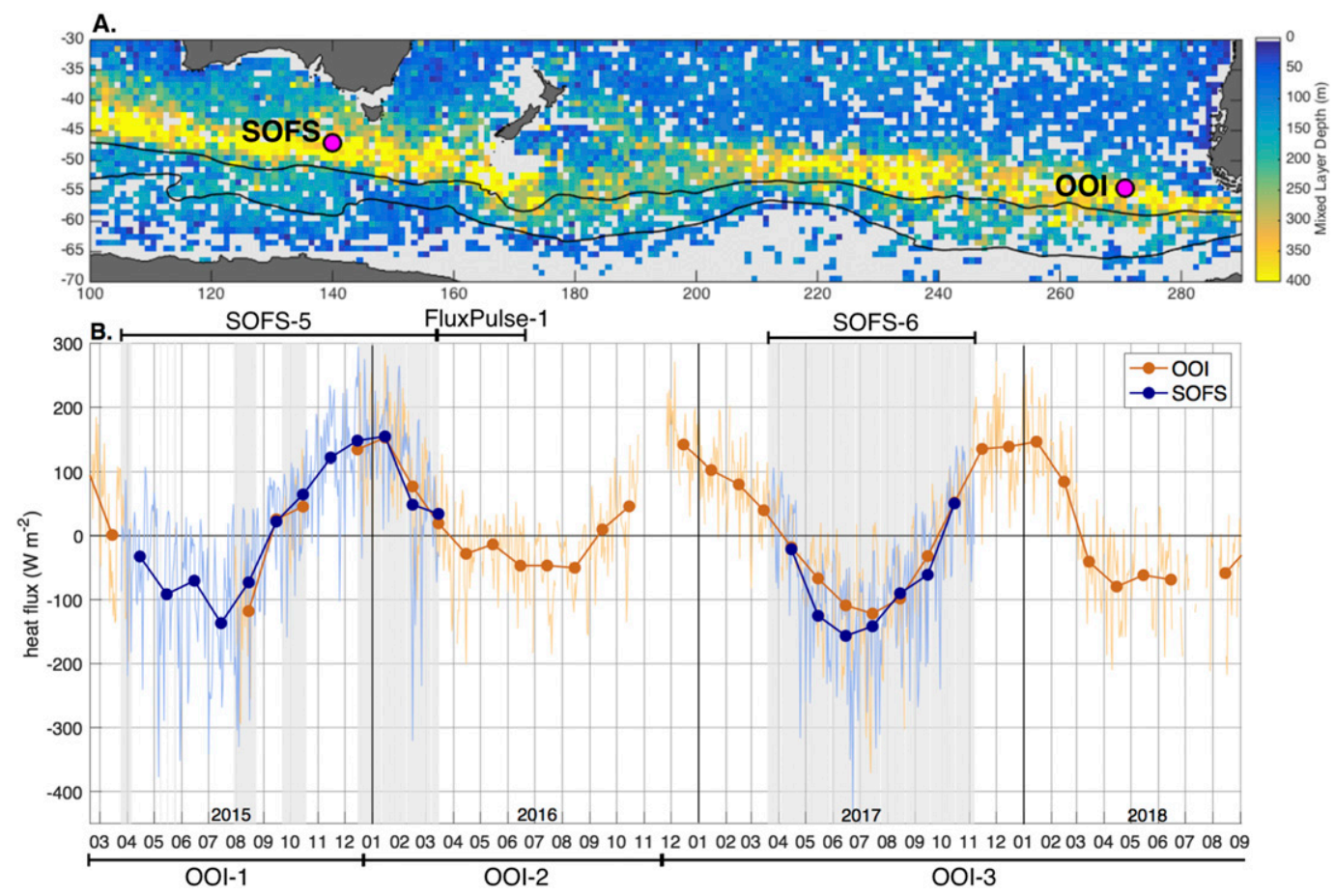

FIG. 1. (a) Map of climatological September mixed layer depth (m) from Holte et al. (2017), showing the position of the SOFS and OOI moorings (magenta circles) and the approximate position of the Subantarctic and Polar Fronts from Orsi et al. (1995) (black lines); (b) time series of net air-sea heat flux (positive into the ocean) at the OOI (orange) and SOFS (blue) moorings during the overlap time period from March 2015 to September 2018. Lighter lines show the daily mean net heat flux, and darker lines and circles indicate the monthly mean net heat flux. Gray shading indicates days where net air-sea heat flux data are available at both moorings.

subduction play a fundamental role in these processes. Wintertime surface ocean heat loss is the leading-order driver of SAMW formation and its interannual variability (Holte et al. 2012; Naveira Garabato et al. 2009). Therefore, accurately quantifying Southern Ocean airsea heat fluxes, particularly in the wintertime, is essential to understanding spatial patterns and temporal variability in oceanic heat and carbon uptake.

The formation of SAMW occurs seasonally in the Southern Ocean. Deep mixed layers, up to $700 \mathrm{~m}$ deep, form on the northern flank of the Subantarctic Front (SAF) in late winter. These thick, homogeneous layers are then subducted into the interior to form SAMW. The thickest SAMW layers are found in the eastern Indian Ocean, and in the south-central and southeast Pacific Ocean (Hanawa and Talley 2001), forming distinct SAMW homogenized "pools," with distinct water mass characteristics (Fig. 1a). Together with cross-front Ekman transport (Rintoul and England 2002) and freshwater fluxes (Iudicone et al. 2008; Cerovečki and Mazloff 2016), wintertime ocean heat loss dominates the formation rate and characteristics of SAMW (e.g., McCartney 1977; Sloyan and Rintoul 2001; Naveira Garabato et al. 2009). However, a number of other processes also strongly influence SAMW formation (Sallée et al. 2010), such as lateral circulation, eddy induced transport, upwelling (Sallée et al. 2010), diapycnal ocean mixing (Sloyan et al. 2010), and eddy heat diffusion (Sallée et al. 2008). As a result, the ocean heat loss and mixed layer depth (MLD) are not necessarily expected to be tightly correlated locally. Additionally, the relative importance of processes important for SAMW formation may be different in the Indian and Pacific Oceans (e.g., Rintoul and England 2002; Sallée et al. 2008; Buongiorno Nardelli et al. 2017). For example, some work indicates that Ekman transport may play a bigger role in SAMW formation in the Indian than the Pacific sector (Rintoul and England 2002).

Strong interannual variability of SAMW formation and characteristics is closely tied to interannual variability in the winter MLD north of the Antarctic Circumpolar Current (Sallée et al. 2010). On interannual time scales, the MLD and the formation of SAMW are modulated by climate modes including El Niño-Southern Oscillation (ENSO) and the southern annular mode (SAM) (Sallée et al. 2010; Naveira Garabato et al. 2009; Close et al. 2013; Buongiorno Nardelli et al. 2017; Kwon 2013; Cerovečki et al. 2019; Meijers et al. 2019). 
Despite the importance of air-sea fluxes for SAMW formation, the remoteness and challenging weather conditions in the Southern Ocean mean that most direct observations of air-sea fluxes, mixed layer deepening and SAMW formation have been made from ship-based studies that are sparse and intermittent in time and space (e.g., McCartney 1977; Hartin et al. 2011; Hanawa and Talley 2001; Holte et al. 2012). While these experiments have yielded important insights into the processes controlling SAMW formation, the lack of ongoing observations has until now prevented comparisons of direct observations of air-sea fluxes in the Indian and Pacific SAMW formation regions. However, recognition of the need for sustained observations of air-sea fluxes in the Southern Ocean, to reduce biases in atmospheric reanalysis flux products, combined with advances in engineering of moorings built to withstand extreme wind and wave conditions (Weller et al. 2012) have led to the deployment of several high-latitude flux moorings in recent years. The Southern Ocean Time Series mooring site, which includes the Southern Ocean Flux Station (SOFS), has been deployed south of Australia intermittently since 2010 (Schulz et al. 2012), while the Ocean Observatories Initiative (OOI) Southern Ocean mooring array has been maintained in the southeast Pacific since early 2015 (Ogle et al. 2018).

The OOI and SOFS moorings offer the first concurrent, multiyear time series of air-sea fluxes in two different sectors of the Southern Ocean. Despite the difference in latitude of the two mooring sites, both are well-placed in key SAMW formation regions north of the Subantarctic Front (SAF): the southeast Indian (SOFS) and southeast Pacific (OOI) (Fig. 1a). These new datasets thus provide a unique opportunity to compare the air-sea flux and upper-ocean variability at the two locations, particularly the intensity of wintertime heat loss events and their impact on the formation of deep winter mixed layers.

Schulz et al. (2012) analyzed extreme heat loss events from the first deployment of the SOFS mooring from March 2010 to March 2011. The authors found a weak annual mean net ocean heat loss of $10 \mathrm{~W} \mathrm{~m}^{-2}$ and showed that extreme turbulent heat loss events are associated with cold air flowing from higher southern latitudes. More recently, Ogle et al. (2018) presented the first analysis of the OOI mooring heat flux time series, finding a weak net ocean heat gain of $29 \mathrm{~W} \mathrm{~m}^{-2}$ for the period from November 2015 to October 2016. However, the exceptionally strong 2015/16 El Niño event (Hu and Fedorov 2017; Santoso et al. 2017) and the observed large interannual variability in wintertime heat loss suggest that this 12 -month mean is unlikely to be representative of the long-term mean. Both the SOFS site
(Schulz et al. 2012) and the OOI site (Ogle et al. 2018) experience strong episodic turbulent heat loss associated with southerly winds bringing cold Antarctic air to the mooring sites. The magnitude of the most "extreme" daily averaged turbulent ocean heat loss (averaged from fluxes calculated using 1-min meteorological observations) recorded from the first deployment of the SOFS mooring $\left(450 \mathrm{~W} \mathrm{~m}^{-2}\right)$ was significantly larger than that recorded at the OOI site $\left(310 \mathrm{~W} \mathrm{~m}^{-2}\right)$. However, as these measurements of extreme heat loss events reported by Schulz et al. (2012) and Ogle et al. (2018) were from different time periods, analysis of concurrent heat loss events is needed to determine whether these differences are indicative of different dynamics at the two mooring locations. This is just one indication that there may be substantial differences in the heat flux and corresponding mixed layer depth variability at the two sites that will provide insights into the role of air-sea fluxes in SAMW formation in these two regions.

In this work, we compare and contrast characteristics and variability of air-sea heat flux, MLD, and SAMW formation from mooring observations in the two key SAMW formation regions. We combine the mooring observations with an Argo gridded product (Roemmich and Gilson 2009) and atmospheric reanalyses to provide temporal and spatial context. The paper is organized as follows. We describe the data and methods in section 2, present a detailed comparison of mooring observations in section $3 a$, investigate the interannual variability and spatial variability in air-sea fluxes and MLDs around the mooring time series using reanalysis and an Argo gridded product, and relate the air-sea heat fluxes to SAMW formation rates in section $3 \mathrm{~b}$. A discussion and the conclusions are presented in section 4 .

\section{Data and methods}

\section{a. Mooring data}

The SOFS mooring site is located southwest of Tasmania at $47^{\circ} \mathrm{S}, 142^{\circ} \mathrm{E}$ (Fig. 1a), as part of the Southern Ocean Time Series site. It was redeployed a total of six times between March 2010 and November 2017 (Table S1 in the online supplemental material). The OOI Apex Surface Mooring (OOI site ID GS01SUMO, hereafter referred to as the OOI mooring) is located at $54.47^{\circ} \mathrm{S}, 89.28^{\circ} \mathrm{W}$, southwest of the South American continent (Fig. 1a). The OOI mooring has had four overlapping deployments beginning in December 2015 (Table S1). Here we include OOI Southern Ocean data through the end of August 2018. The time period analyzed in this study is April 2015September 2018, spanning SOFS-5, FluxPulse-1, SOFS-6, and the first three OOI mooring deployments. 
Both moorings are mounted with duplicate Air-Sea Interaction Meteorological (ASIMET) packages, which measure air temperature, air humidity, barometric pressure, precipitation, zonal and meridional wind components, sea surface temperature (SST), and downwelling shortwave and longwave radiation (Hosom et al. 1995). Analysis of measurement quality for ASIMET sensors has been previously done at midlatitudes (Colbo and Weller 2009) and in the Gulf Stream (Bigorre et al. 2013). The net air-sea heat flux $Q_{\mathrm{NET}}$ (positive into the ocean), net shortwave radiation $Q_{\mathrm{Sw}}$, net longwave radiation $Q_{\mathrm{LW}}$, sensible heat flux $Q_{\mathrm{SH}}$, and latent heat flux $Q_{\mathrm{LH}}$ are calculated from the 1-min meteorological observations using the COARE 3.5 flux algorithm (Edson et al. 2013), then averaged to daily average flux terms.

Past analyses of ASIMET observations in the subtropics find an error in total net heat fluxes of $8 \mathrm{~W} \mathrm{~m}^{-2}$ (Colbo and Weller 2009), while recent analyses of the OOI Irminger Sea mooring (deployed at $60^{\circ} \mathrm{N}$ ) indicate errors in the net heat flux of approximately $6 \mathrm{~W} \mathrm{~m}^{-2}$. A comparison of the two ASIMET sensor packages mounted on the OOI mooring by Ogle et al. (2018) shows mean differences between the two sensors of each heat flux component of $5 \mathrm{~W} \mathrm{~m}^{-2}$ or less, with RMS errors less than $8 \mathrm{~W} \mathrm{~m}^{-2}$ for each component apart from $Q_{\mathrm{SW}}$ (RMS errors $26 \mathrm{~W} \mathrm{~m}^{-2}$ for deployment 1 and $15 \mathrm{~W} \mathrm{~m}^{-2}$ for deployment 3) and $Q_{\mathrm{LH}}$ (RMS error $20 \mathrm{~W} \mathrm{~m}^{-2}$ for deployment 2). Schulz et al. (2012) did similar comparisons for the SOFS mooring yielded a mean difference of daytime $Q_{\mathrm{SW}}$ of $6 \mathrm{~W} \mathrm{~m}^{-2}$ and an RMS error of $7 \mathrm{~W} \mathrm{~m}^{-2}$. For $Q_{\mathrm{LW}}$ the mean difference is $0.2 \mathrm{~W} \mathrm{~m}^{-2}$ and RMS error is $1.5 \mathrm{~W} \mathrm{~m}^{-2}$. Comparison of SOFS fluxes with shipboard fluxes showed a mean bias in $Q_{\mathrm{NET}}$ of $-4 \mathrm{~W} \mathrm{~m}^{-2}$, and Schulz et al. (2012) concluded that the accuracy of SOFS mooring measurements was within the range found for previous ASIMET observations. Based on the error analysis of the OOI Southern Ocean mooring (Ogle et al. 2018) and the SOFS mooring (Schulz et al. 2012), as well as recent analysis of the OOI Irminger Sea mooring (Josey et al. 2019), we estimate the accuracy of $Q_{\mathrm{NET}}$ to be within $10 \mathrm{~W} \mathrm{~m}^{-2}$ at both moorings.

For the FluxPulse-1 deployment at the SOFS site, the dual ASIMET humidity sensors both failed by 26 March 2016, around 10 days into the deployment, and therefore no fluxes were calculated for this deployment. However, net shortwave radiation, wind speed and direction, SST, and air temperature are all available. After quality control of both datasets, there are 379 days of overlapping daily averaged $Q_{\mathrm{NET}}, Q_{\mathrm{LW}}, Q_{\mathrm{SH}}$, and $Q_{\mathrm{LH}}$. There are 568 days of overlapping $Q_{\mathrm{SW}}$ when including the FluxPulse-1 deployment.

Mooring deployments and configuration are summarized in Table S1. A more detailed description of the mooring configuration and data processing from the OOI mooring is provided by Ogle et al. (2018). Here we use the same quality controlled air-sea flux data for February 2015-August 2017 as presented by Ogle et al. (2018) and extend the time series from August 2017 until the end of August 2018. More details on the SOFS mooring configuration and data processing are described in Schulz et al. (2012).

In addition to the mooring surface flux data, we use subsurface temperature and salinity data from each mooring site. At the OOI site, the data are from a profiler mooring collocated with the surface mooring, which contains two wire-following McLane Moored Profilers that provide CTD profiles below $180 \mathrm{~m}$. We also utilize CTD data from two flanking subsurface moorings each located $55 \mathrm{~km}$ from the surface and profiler moorings, forming a triangular configuration. Each flanking mooring is mounted with 12 fixed-depth CTDs between 30 and $1500 \mathrm{~m}$. At the SOFS mooring, subsurface CTDs and temperature sensors are deployed at different depths for each deployment. We focus on the SOFS-6 deployment, which had Minilog II temperature sensors attached to the mooring at 28 fixed depths between the surface and 500-m depth. The other SOFS deployments lack subsurface data with sufficient vertical resolution to accurately capture MLD variability. We calculate Conservative Temperature from the in situ measurements and use this throughout the analysis and figures.

MLD is calculated from the subsurface data at the OOI and SOFS moorings using a temperature threshold of $0.1^{\circ} \mathrm{C}$ relative to near-surface temperature, and at the OOI mooring we also calculate the MLD using an $0.03 \mathrm{~kg} \mathrm{~m}^{-3}$ density threshold (de Boyer Montégut et al. 2004). The SOFS mooring only has subsurface temperature data with sufficient vertical resolution to track MLD evolution; therefore we cannot calculate MLD with a density criterion and thus use the temperature threshold definition of MLD to compare the two moorings. We note that the $0.1^{\circ} \mathrm{C}$ threshold chosen is smaller than typical temperature thresholds used to determine MLDs globally, which are $0.2^{\circ} \mathrm{C}$ or greater (de Boyer Montégut et al. 2004). We have chosen to use the $0.1^{\circ} \mathrm{C}$ threshold because it had the closest agreement with the MLD using a $0.03 \mathrm{~kg} \mathrm{~m}^{-3}$ density threshold at the OOI mooring. At the SOFS mooring, where there are temperature data from the surface to $500 \mathrm{~m}$, we use the temperature at $10 \mathrm{~m}$ as the near-surface reference temperature following de Boyer Montégut et al. (2004). For the OOI mooring site, we use the subsurface profiler mooring temperature data to calculate MLDs when the MLD is below 180-m depth following Ogle et al. (2018). Because there are no near-surface data at the profiler mooring, we use near-surface data from the nearby Flanking Mooring B 
CTD at 30-m depth as it has the most continuous temporal coverage. This also assumes that when MLDs are detected below $180 \mathrm{~m}$ at the profiler mooring that there the temperature and density are relatively constant and does not cross the threshold between 30- and 180-m depth where there are no data available. We note that MLDs using the Flanking mooring A 30-m CTD instead as reference are very similar. We use an Argo gridded product of temperature and salinity (Roemmich and Gilson 2009) to extend the short time series of mooring MLD. We note that while the Argo gridded product has been checked extensively for consistentency with other observations and satellitederived products, the errors due to undersampling are greater in the high latitudes, particular south of $50^{\circ} \mathrm{S}$ where the OOI mooring is located (Roemmich and Gilson 2009). We refer to Ogle et al. (2018, their Fig. S2) for a comparison of wintertime MLDs from individual Argo profiles in the region surrounding the OOI mooring for the winter of 2015 and 2016. To compare Argo time series to the mooring observations, we choose the closest Argo grid point $\left(1^{\circ}\right.$ latitude-longitude grid) to each mooring location. The distance between the closest Argo grid point and the OOI subsurface profiler mooring is approximately $15 \mathrm{~km}$, and the distance between the closest Argo grid point and the SOFS mooring is approximately $38 \mathrm{~km}$ (noting that the precise mooring positions vary slightly over time with deployment and mooring movement due to wind and strong currents). Argo MLD is calculated using a $0.03 \mathrm{~kg} \mathrm{~m}^{-3}$ density threshold (de Boyer Montégut et al. 2004), and we compare the MLD from the moorings and Argo product in section $3 \mathrm{a}$.

Finally, we use the fifth major global reanalysis produced by the European Centre for Medium-Range Weather Forecasts (ERA5) (Copernicus Climate Change Service (C3S) 2017) product, and the NCEP-NCAR reanalysis (Kalnay et al. 1996), hereafter referred to as NCEP, to provide temporal and spatial context for the mooring data. While there are many more reanalysis flux products available, for simplicity we directly compare only ERA5 to the mooring data, as the goal of this work is to understand the variability in fluxes and MLD from the moorings rather than to assess the performance of reanalysis products against the mooring observations. To compare ERA5 time series to the mooring observations, we choose the closest ERA5 grid point (on an interpolated regular $0.25^{\circ}$ latitude-longitude grid) to each mooring location. The distance between the closest ERA5 grid point and the OOI mooring location is approximately $4 \mathrm{~km}$, and the distance between the closest ERA5 grid point and the SOFS mooring is less than $1 \mathrm{~km}$. In addition, for the spatial context surrounding the mooring in section $3 \mathrm{~b}$ we repeat the analyses with both ERA5 and NCEP in order to provide greater confidence in the observed spatial patterns and temporal variability.

\section{b. Water mass transformation analysis}

A natural way to estimate the formation of SAMW is by determining the changes in volume of a density layer encompassing SAMW. Changes in the volume of a density layer occur as a result of diabatic processes, which include both surface air-sea buoyancy fluxes and diapycnal ocean mixing, the latter occurring predominantly in the near-surface layer. The water mass transformation framework quantifies the volume changes of a given density layer due to diabatic processes by estimating volume flux across an isopycnal surface (Groeskamp et al. 2019). Such a framework was introduced by Walin (1982), who considered temperature surfaces, and was first applied to density layers by Speer and Tziperman (1992). The convergence or divergence of the water mass transformation in a given isopycnal layer yields water mass formation, which quantifies the rate at which water has been formed (or destroyed) in this layer (e.g., Marshall et al. 1999; Nurser et al. 1999; Iudicone et al. 2008; Groeskamp et al. 2019). Although ocean mixing plays an important role in water mass formation in the Southern Ocean (Sloyan and Rintoul 2001; Iudicone et al. 2008; Cerovečki and Mazloff 2016), here we focus on the relationship between air-sea fluxes and SAMW formation rates, and consequently only estimate the component of transformation due to surface buoyancy fluxes. We consider a layer of water designated by $\sigma$ within the density range $\sigma-\Delta \sigma$ and $\sigma+\Delta \sigma$ that outcrops at the sea surface. Water mass transformation $F(\sigma, t)$ in such a layer can be obtained as an area integral of air-sea buoyancy flux $B$ over this outcrop window. A discretized expression for $F(\sigma, t)$ (e.g., Maze et al. 2009) is

$$
F(\sigma, t)=\frac{1}{\Delta \sigma} \iint_{\sigma-\frac{\Delta \sigma}{2}}^{\sigma+\frac{\Delta \sigma}{2}} B d A,
$$

in which $d A$ is an area element of integration, and this represents an integral over a discrete isopycnal outcrop. The buoyancy flux $B$ is given by

$$
B=\frac{\alpha Q_{\mathrm{NET}}}{C_{P}}+\rho_{0} \beta S(E-P-R) .
$$

Here $\rho_{0}$ is a reference density $1025 \mathrm{~kg} \mathrm{~m}^{-3}, \alpha$ is the thermal expansion coefficient, $\beta$ is the saline contraction coefficient, $C_{P}$ is the specific heat, $S$ is salinity, $E$ is evaporation, $P$ is precipitation, and $R$ is runoff. Positive $F(\sigma, t)$ indicates transformation toward denser water. 
The convergence of water mass transformation $F(\sigma, t)$ with respect to density yields the water mass formation $M(\sigma, t)$ :

$$
M(\sigma, t)=F\left(\sigma-\frac{\Delta \sigma}{2}\right)-F\left(\sigma+\frac{\Delta \sigma}{2}\right) .
$$

In practice $M(\sigma, t)$ is multiplied by $\Delta \sigma$ so that it has the same units as the transformation rate $\left(\mathrm{m}^{3} \mathrm{~s}^{-1}\right.$, expressed in Sverdrups, $\left.1 \mathrm{~Sv} \equiv 10^{6} \mathrm{~m}^{3} \mathrm{~s}^{-1}\right)$. The formation rate estimates considered in this work were obtained using daily averaged net air-sea heat flux, SST, and $E-P$ from ERA5 reanalysis as inputs. They were combined with monthly averaged salinity (interpolated to daily values) from the uppermost layer (2.5-m depth) of the gridded Argo product (Roemmich and Gilson 2009). This mismatch in both data sources and spatiotemporal sampling represents a potential source of error in the water mass formation estimates, as the individual features (such as the Antarctic Circumpolar Current fronts) may not be collocated in the two datasets. Because we only focus on transformation at the sea surface, we use potential density referenced to the sea surface as the density coordinate for the water mass transformation. However, to show the robustness of our results and to aid in the comparison to other works, we additionally show the results of the same calculation using neutral density $\gamma_{N}$ (Jackett and McDougall 1997). Comparison of the results using the two density coordinates is discussed in section $3 b$.

\section{Results}

\section{a. Mooring observations of heat fluxes and mixed layers}

Although the SOFS mooring position is farther equatorward than the OOI mooring, both moorings are located in regions of strong wintertime ocean heat loss leading to the formation of deep winter mixed layers (Fig. 1a). The overlapping time series of net air-sea heat flux from the OOI and SOFS moorings show that seasonal variations in the net air-sea heat fluxes are very similar at both sites, as the net air-sea heat flux is dominated by the strong seasonal cycle in shortwave radiation (Figs. 1b and 2). The shortwave and longwave components are somewhat stronger in magnitude at the SOFS mooring than at the OOI mooring (Figs. 2a,b) because the more equatorward position of the SOFS mooring leads to both stronger incoming solar radiation and higher SST. The differences between the two moorings' monthly means of the $Q_{\mathrm{SW}}$ and $Q_{\mathrm{LW}}$ appear to be consistent during the time when the mooring data are overlapping (Figs. 2a,b). However, there may be temporal variations in the difference in $Q_{\mathrm{LW}}$ due to anomalies of SST and cloudiness at the two mooring sites that are not revealed in the short overlap time period. The magnitude and variability of turbulent heat flux components are generally more similar at SOFS and OOI than the radiative fluxes (Figs. 2c,d). A notable exception occurs in the austral winter of 2017 (and to a lesser extent in February and March of 2016), when the $Q_{\mathrm{LH}}$ is significantly stronger at the SOFS mooring than at the OOI mooring (Fig. 2c), while the $Q_{\mathrm{SH}}$ is of a similar magnitude. The enhancement of $Q_{\mathrm{LH}}$ but not $Q_{\mathrm{SH}}$ measured by the SOFS mooring indicates that air-sea humidity differences rather than just stronger winds at the SOFS mooring site are responsible for the stronger heat flux at the SOFS site. We further investigate the role of different atmospheric regimes in the difference in $Q_{\mathrm{LH}}$ at the two moorings later in this section.

In the years when mooring observations are available, there is no consistent structure to the seasonality in $Q_{\mathrm{LH}}$ and $Q_{\mathrm{SH}}$ at the two mooring sites (Figs. 2c,d). In 2017, when data from both moorings span the full winter, the turbulent heat flux $\left(Q_{\mathrm{LH}}+Q_{\mathrm{SH}}\right)$ at both moorings showed almost symmetric seasonality, with maximum turbulent heat loss in austral winter from June to September and weaker heat loss before and after. However, such a pattern is not so clear in the other years observed. In 2015, the monthly mean turbulent heat fluxes at the OOI mooring decreased through March and April, but data are missing for most of the winter, so it is unclear if the stronger turbulent heat loss was sustained through the winter, although August data indicate strong turbulent heat loss. In contrast, in 2016 when only data from the OOI mooring were available for the entire year, there is no winter enhancement in turbulent heat flux, while in 2018, there was stronger turbulent heat loss in autumn (March, April, May) that decreased later in the winter (Figs. 2c,d).

Since the strong wintertime ocean heat loss events play an instrumental role in mixed layer deepening (e.g., Holte et al. 2012), we further investigate the frequency and magnitude of intermittent daily averaged turbulent heat loss $\left(Q_{\mathrm{LH}}+Q_{\mathrm{SH}}\right)$ events (Fig. 3). Considering the entire record from 2015 to September 2018 (excluding gaps in the time series in winter 2015 and late 2016), the mean turbulent heat flux at the OOI mooring is $-57 \mathrm{~W} \mathrm{~m}^{-2}$, with a standard deviation of $52 \mathrm{~W} \mathrm{~m}^{-2}$. At the SOFS mooring the mean turbulent heat flux for the full SOFS time period is $-80 \mathrm{~W} \mathrm{~m}^{-2}$, and the standard deviation is $73 \mathrm{Wm}^{-2}$. For days when data from both moorings are available, the OOI mean is $-63 \mathrm{~W} \mathrm{~m}^{-2}$, with a standard deviation of $57 \mathrm{~W} \mathrm{~m}^{-2}$, while the SOFS mean is $-94 \mathrm{~W} \mathrm{~m}^{-2}$ with a standard deviation of $77 \mathrm{~W} \mathrm{~m}^{-2}$. This indicates substantially stronger and more variable 

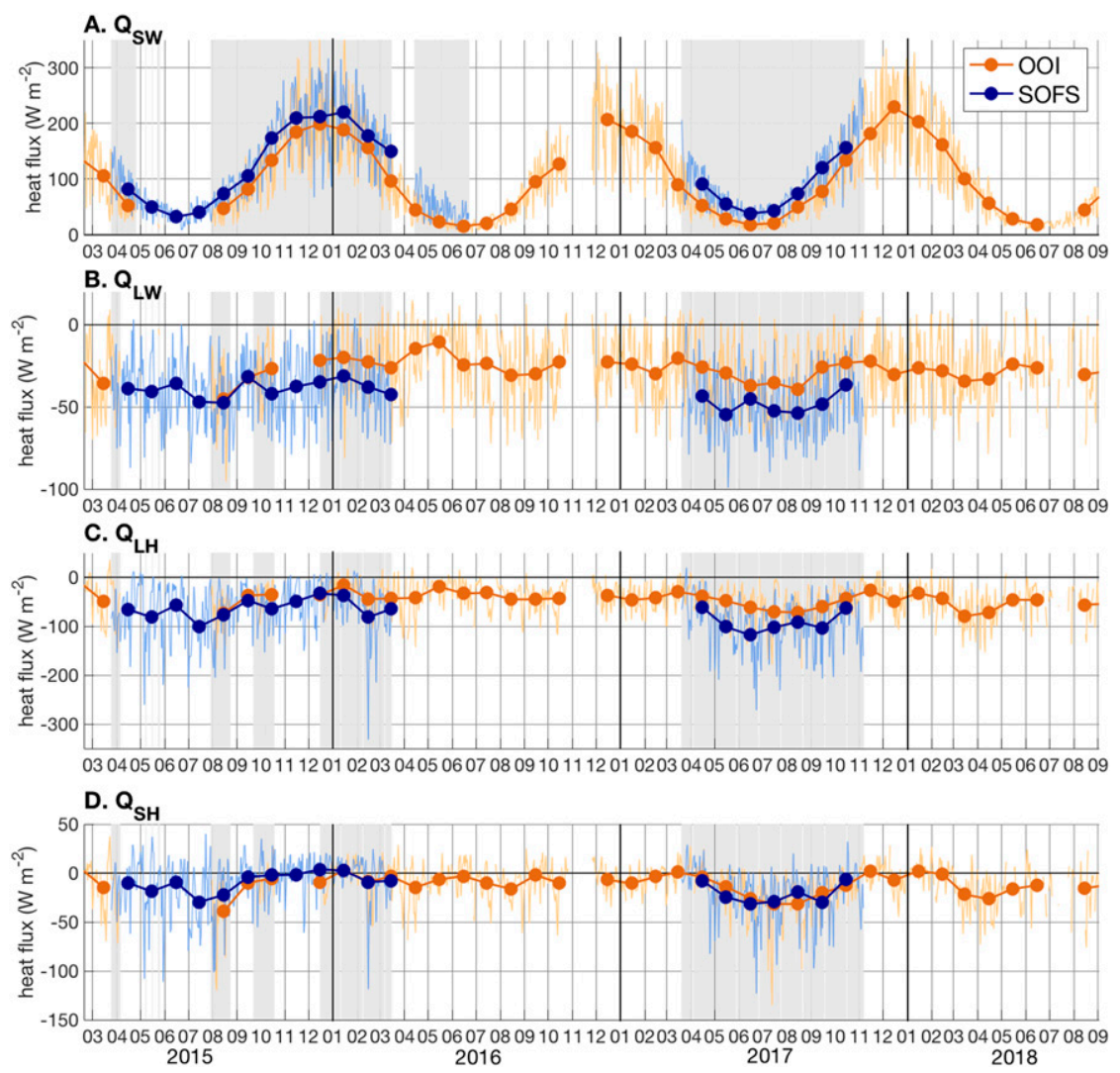

FIG. 2. Time series of (a) $Q_{\mathrm{SW}}$, (b) $Q_{\mathrm{LW}}$, (c) $Q_{\mathrm{LH}}$, and (d) $Q_{\mathrm{SH}}$ at the OOI and SOFS moorings from March 2015 to September 2018. Lighter lines show the daily mean fluxes and darker lines and circles indicate the monthly mean fluxes. Gray shading indicates days when air-sea heat flux component data are available at both moorings.

turbulent heat fluxes at the SOFS mooring than at the OOI mooring, with the average turbulent heat flux at the SOFS mooring during the common time period 1.5 times that observed at the OOI mooring. We note that because the seasonal cycle in turbulent heat loss is weak compared to higher-frequency variability and the time series is short, we have not removed a seasonal cycle or longer-term signal before comparing the characteristics of turbulent heat loss at the two moorings.

At each mooring we define turbulent heat loss events as time periods when the daily mean turbulent heat flux is from one to two standard deviations below the mean of all daily average values (for the overlap time period only and for the full record at each mooring) and extreme heat loss events as those that are two or more standard deviations below the mean. This definition is used to be consistent with the definition of extreme heat loss events used by Ogle et al. (2018). Using this criterion, we identify 78 extreme events at the OOI mooring, and 81 extreme events at the SOFS mooring (when considering the full SOFS time period from 2010 to 2017). During the overlap time period, when observations from both moorings are available, there are 32 extreme events at the OOI mooring, and 31 extreme events at the SOFS mooring (Figs. 3a,b).

At both mooring locations, heat loss events are more frequent in austral autumn (MAM) and winter (JJA), and the total number of extreme events at both moorings in the autumn and winter is more than double the number of events in spring and summer (Fig. 3c). All of the 10 extreme heat loss events greater than three standard deviations below the mean at the OOI mooring and 8 of the 11 events at the SOFS mooring occur in autumn and winter. We note that the SOFS data during the overlap time period are slightly biased toward winter sampling (58\% of days with turbulent heat flux data at the SOFS mooring are during austral autumn and winter, with the remaining $42 \%$ during austral spring and summer), and so this may affect the seasonal frequency of extreme heat loss events at the SOFS site. At each mooring, we counted the number of daily heat loss events (at least one standard deviation below the mean turbulent heat loss from each mooring during the overlapping time period from March 2015 to August 2018) 

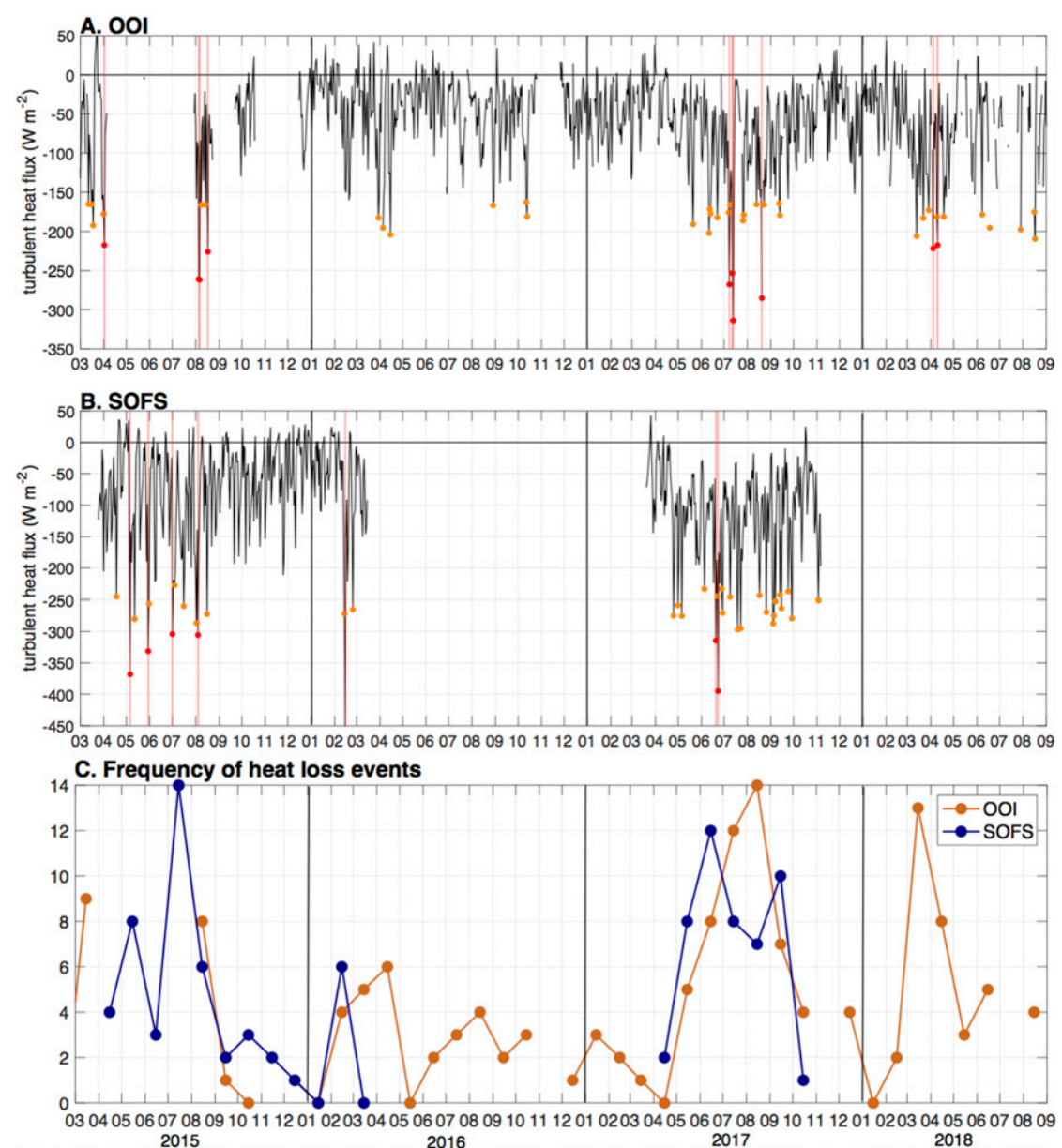

FIG. 3. Time series of turbulent (latent plus sensible) heat flux at (a) OOI and (b) SOFS, and (c) the number of days where the daily mean turbulent heat loss events exceeds one standard deviation below the mean in each month at the OOI and SOFS moorings. Red dots and lines in (a) and (b) indicate "extreme" heat loss events (greater than three standard deviations below the mean) and orange dots indicate "intense" heat loss events (greater than two standard deviations below the mean).

for each month during the overlap time period (Fig. 3c). There is a positive correlation between the number of heat loss events per month at SOFS and OOI, with a correlation coefficient of $0.64(p<0.01)$.

To further characterize the differences in heat fluxes at the two moorings we compare probability density functions (PDFs) of daily averaged heat flux components (Fig. 4) for days when all heat flux component data are available at both moorings. Although the mean $Q_{\text {sw }}$ and $Q_{\mathrm{LW}}$ have a larger magnitude at the SOFS mooring relative to the OOI mooring due to its equatorward position, the standard deviation of both terms is similar at the two sites (Figs. 4a,b). The $Q_{\mathrm{LH}}$ distribution differs substantially between the two moorings: the mean heat loss at the SOFS mooring is more than $20 \mathrm{Wm}^{-2}$ stronger with a larger standard deviation (Fig. 4c). At both moorings, the distribution is skewed with a long tail of stronger $Q_{\mathrm{LH}}$, and the SOFS mooring has a substantial fraction of days with latent heat loss greater than $150 \mathrm{~W} \mathrm{~m}^{-2}$, while the OOI mooring has very few days of this magnitude. In contrast, the distribution of $Q_{\mathrm{SH}}$ is very similar at the two moorings, although the SOFS mooring has a slightly larger standard deviation (Fig. 4d).

The stronger total wintertime heat losses measured at the SOFS site are mostly due to larger magnitude $Q_{\mathrm{LH}}$, and to a lesser extent $Q_{\mathrm{LW}}$. The distribution of wind speed at the two moorings indicates that the mean wind speed is similar at the two moorings $\left(9.9 \mathrm{~m} \mathrm{~s}^{-1}\right.$ at OOI and $10.3 \mathrm{~m} \mathrm{~s}^{-1}$ at SOFS) (Fig. 5). However, high wind speeds $\left(>15 \mathrm{~m} \mathrm{~s}^{-1}\right)$ are more frequent at the SOFS site, which contributes to larger turbulent heat fluxes (Fig. 5a). If stronger winds were the main driver of stronger $Q_{\mathrm{LH}}$ at the SOFS mooring compared to the OOI mooring, then we would expect the $Q_{\mathrm{SH}}$ to also be 

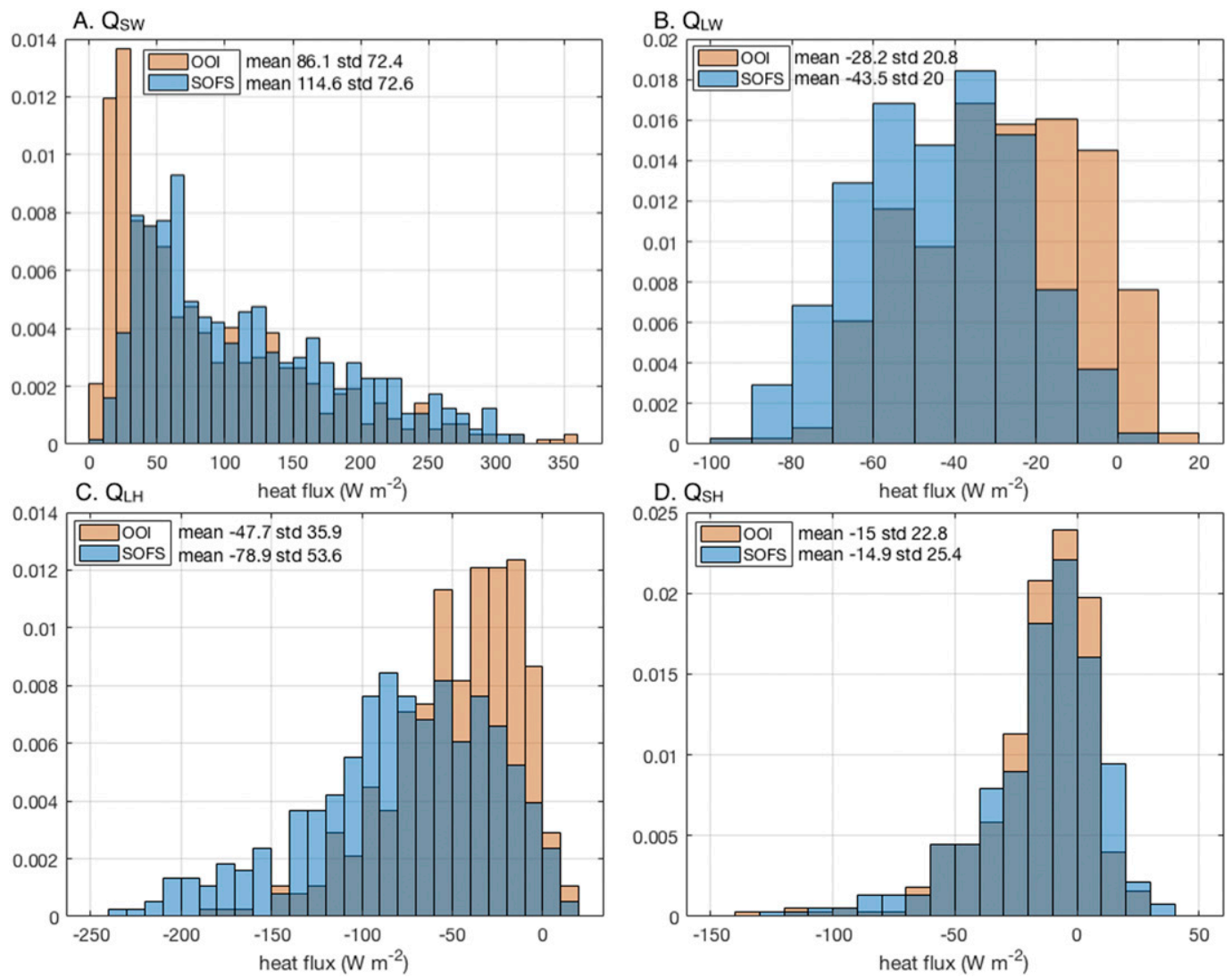

FIG. 4. Probability density functions of daily averaged (a) net shortwave radiation, (b) net longwave radiation, (c) latent heat flux, and (d) sensible heat flux for the overlapping time period at the OOI and SOFS moorings. All heat flux components PDFs are binned in $10 \mathrm{~W} \mathrm{~m}^{-2}$ wide bins.

significantly enhanced at the SOFS site. Instead the enhanced $Q_{\mathrm{LH}}$ is partly a result of larger air-sea humidity differences at the SOFS mooring, while the distribution of air-sea temperature difference is similar at the two moorings (Figs. 5c,d). The larger humidity differences at the SOFS mooring occur because of the nonlinear relationship between temperature and humidity: the SST is warmer at the SOFS site due to its more equatorward position (for the overlapping days the mean SST measured at the OOI mooring is $6.7^{\circ} \mathrm{C}$ and at the SOFS mooring is $10.7^{\circ} \mathrm{C}$ ), and thus the sea surface saturation humidity is substantially higher. However, the relationship between wind direction, air humidity and latent heat flux differs at the two sites, indicating that the stronger latent heat flux observed at the SOFS site may also be attributed to different wind regimes (Fig. 6).

Our results suggest that there are two atmospheric regimes responsible for episodic heat loss events $\left(Q_{\mathrm{LH}}>\right.$ $100 \mathrm{~W} \mathrm{~m}^{-2}$ ) at the SOFS mooring, but only one dominates at the OOI mooring (Fig. 6). A number of strong latent heat loss events occur at the SOFS mooring when winds are northwesterly (we follow the atmospheric convention such that northwesterly winds are defined as winds coming from the northwest), while no latent heat loss events of comparable magnitude occur at the OOI mooring (Fig. 6a). To further relate the frequency of strong latent heat loss events to wind regimes, for each mooring we show a PDF of wind direction for days when the daily mean $Q_{\mathrm{LH}}$ exceeds $100 \mathrm{~W} \mathrm{~m}^{-2}$ (Fig. 6b). Note that because seasonality in $Q_{\mathrm{LH}}$ is weak, we use the full time series from both moorings to identify strong latent heat loss days in Fig. 6, but the PDF is very similar when calculated using the overlapping time period only. The mean of wind directions for strong $Q_{\mathrm{LH}}$ days is substantially shifted toward more northerly winds at the SOFS mooring (mean wind heading $100^{\circ}$ ) relative to OOI (mean wind heading $119.7^{\circ}$ north of east). SOFS wind directions also have a larger standard deviation and are skewed farther toward northerly winds (Fig. 6b). This results in $40 \%$ of all latent heat loss events (daily mean exceeding $100 \mathrm{~W} \mathrm{~m}^{-2}$ ) occurring with northerly at the SOFS mooring, compared to only $18 \%$ at the OOI mooring. This indicates that the single regime of turbulent 
A. wind speed

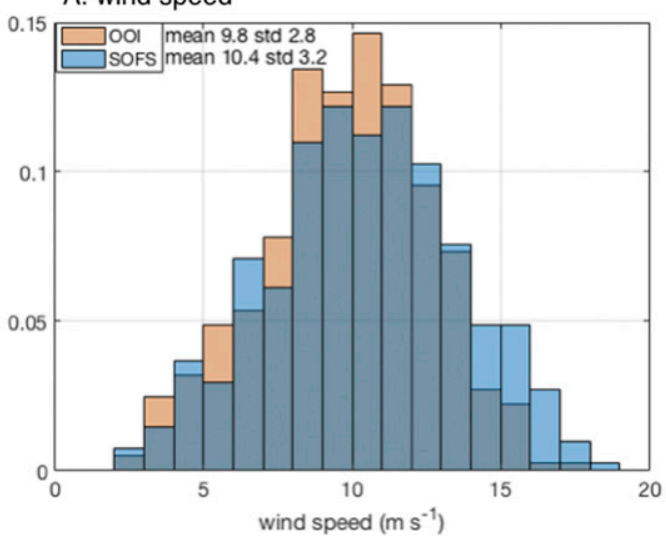

C. temperature difference

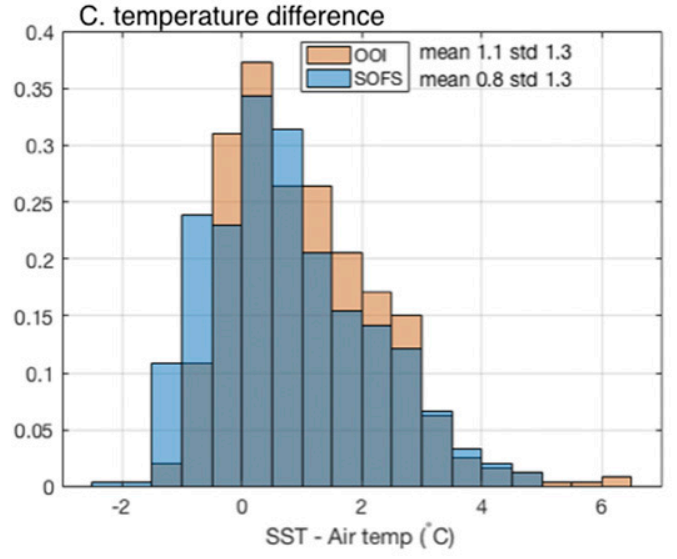

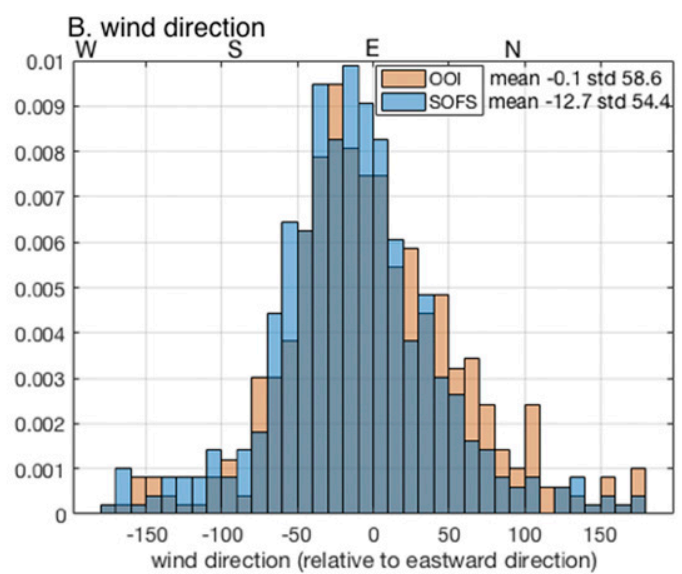

D. humidity difference

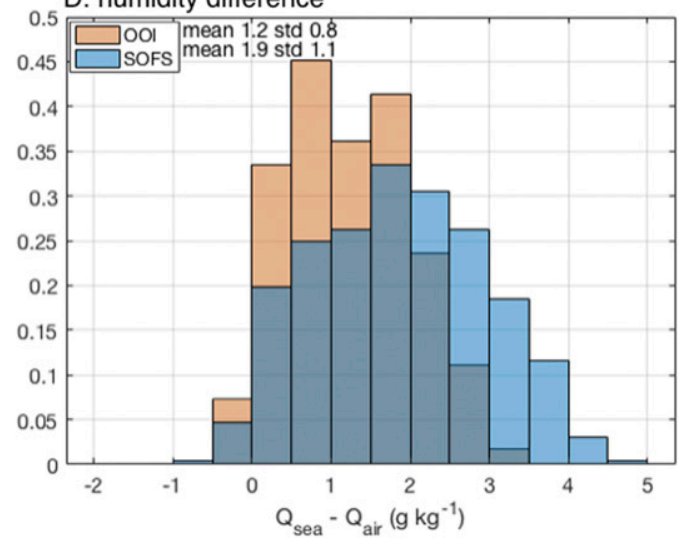

FIG. 5. Probability density functions of daily averaged (a) wind speed, (b) wind direction, (c) sea-air temperature difference, and (d) sea-air humidity difference for the overlapping time period at the OOI and SOFS moorings. Letters N, E, S, and W above (b) indicate northward, eastward, southward, and westward wind directions, respectively.

heat loss events driven by cold air originating from the south described by Schulz et al. (2012) and Ogle et al. (2018) dominates at the OOI mooring, but not at the SOFS mooring. Instead, there is a second regime of strong turbulent heat loss at the SOFS site, driven by relatively dry air originating from the north. The presence of the Australian continent north of the SOFS site leads to relatively dry air being advected from the north, relative to the oceanic air at the OOI mooring in the southeast Pacific.

Both the OOI and SOFS surface flux moorings have collocated or nearby subsurface temperature data with high enough vertical and temporal resolution to allow examination of the mixed layer response to episodic heat loss events during 2016 and 2017 (Fig. 7). Near the OOI surface mooring, the subsurface profiler has temperature and salinity data below $180 \mathrm{~m}$ for all of 2016 and 2017, showing the formation of deep mixed layers $>180 \mathrm{~m}$ in the winter (Fig. 7b). At the SOFS mooring, subsurface temperature data in the upper $500 \mathrm{~m}$ with sufficient resolution to resolve changes in the mixed layer on the order of $10 \mathrm{~m}$ are only available for the SOFS-6 deployment, which includes the full winter of 2017 and captures deep winter mixed layers (Fig. 7d). At the OOI mooring we show MLD calculated using both a density threshold (gray line in Fig. 7b) and temperature threshold (gray line in Fig. 7d) for comparison with the SOFS mooring where only temperature measurements are available. The density threshold method yields a substantially shallower MLD in the winter of 2016 and in July and August of 2017 at the OOI mooring, suggesting that the MLD estimates based on temperature only may be biased deep although it is unclear if this also applies to the SOFS mooring. MLDs from the Argo gridded product (Roemmich and Gilson 2009) (purple circles and lines in Figs. $7 b$ and $7 d$ ) tend to be shallower than those observed at the OOI mooring, although there is good agreement with the density threshold-based MLD in early winter 2017. At the SOFS mooring, the Argo gridded MLDs agree reasonably well with the mooring for most of 2017, but with Argo substantially overestimating MLDs during August and September 2017. 


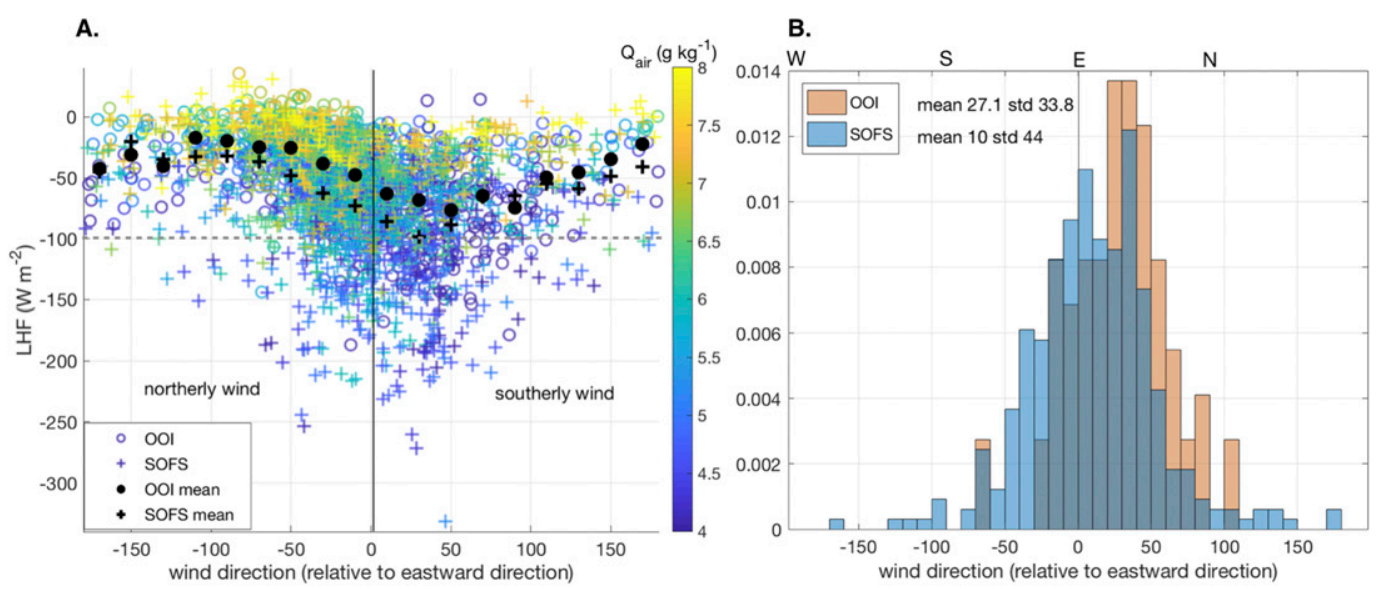

FIG. 6. (a) Scatterplot of daily averaged latent heat flux and wind direction (expressed in degrees from eastward direction), colored by specific humidity for OOI (circles) and SOFS (crosses). Black circles (OOI) and crosses (SOFS) show the mean latent heat flux of all daily averages in $20^{\circ}$ wind direction bins; (b) probability density function of wind direction for days with mean latent heat flux $<-100 \mathrm{~W} \mathrm{~m}^{-2}$ for the OOI and SOFS moorings. The dashed line in (a) indicates $100 \mathrm{~W} \mathrm{~m}^{-2}$ latent heat loss. Positive wind directions indicate a southerly wind (bringing cold air from the south over the mooring sites), and negative wind directions indicate northerly winds.

From these short overlap time period and the difference in temporal resolution of these datasets it is not possible to infer a consistent bias between the mooring MLDs and the Argo product.

There are weak, but statistically significant, negative correlations between daily averaged net heat flux and MLD (calculated from an $0.1^{\circ} \mathrm{C}$ temperature threshold, black lines in Figs. 7b and 7d) at both the OOI and SOFS moorings during the winter of 2017 where both net heat flux and MLD values are available at both moorings, with correlation coefficients between net heat flux and MLD of -0.35 at OOI and -0.38 at SOFS $(p<0.01)$. These fairly weak correlations on daily time scales indicate that freshwater flux, wind-driven mixing and lateral oceanic processes may also influence MLD on these time scales (Sloyan et al. 2010; Holte et al. 2012; Rintoul and England 2002). The correlation between heat flux and MLD on longer time scales is discussed in section 3b. Previous work supports this: for example, Holte et al. (2012) found that the wintertime MLDs in the southeast Pacific cannot be represented using a one-dimensional mixed layer model forced by buoyancy fluxes alone, but were well represented when forced with both buoyancy fluxes and wind stress, and when preconditioning was included. Investigation into the relative role of ocean advection and mixing on mixed layer development on subannual time scales is beyond the scope of this current work.

Both moorings have partial or complete wintertime data for two of the three years $(2015,2016,2017)$, allowing a first look at year-to-year variability of wintertime heat fluxes. Observations from the OOI mooring are available for only two full austral winters (JJA) in 2016 and 2017, but they reveal striking differences (Figs. 1b, 2, and a3a). The wintertime (JJA) mean net air-sea heat flux indicates surface ocean heat loss of $48 \mathrm{~W} \mathrm{~m}^{-2}$ in winter 2016 (JJA) and $110 \mathrm{~W} \mathrm{~m}^{-2}$ in winter 2017, a difference of $62 \mathrm{~W} \mathrm{~m}^{-2}$. The ERA5 reanalysis had wintertime mean heat loss at the OOI mooring location of $73 \mathrm{~W} \mathrm{~m}^{-2}$ in 2016 , and $139 \mathrm{~W} \mathrm{~m}^{-2}$ in 2017. ERA5 overestimates the wintertime heat loss at the OOI mooring by about $30 \mathrm{~W} \mathrm{~m}^{-2}$, but accurately captures the year-toyear difference over the 2-yr period analyzed $\left(66 \mathrm{~W} \mathrm{~m}^{-2}\right)$. Although data are not available for much of winter 2015 at the OOI mooring, the August 2015 observations indicate strong heat loss, similar to winter 2017. This year to year variability in wintertime heat loss will be explored in more detail using the ERA5 reanalysis in section $3 b$.

At the OOI location, the difference between the two fully sampled winters, 2016 and 2017, is particularly evident in the cumulative ocean heat loss from 1 April onward (Fig. 8a), a quantity of central importance for development of deep wintertime mixed layers associated with SAMW formation. Very weak wintertime ocean heat loss at the OOI mooring in 2016 was likely associated with the extreme El Niño event peaking in 2015/16 (Stuecker et al. 2017). Together with the SAM, ENSO strongly influences SST and SAMW formation properties in the southeast Pacific (Naveira Garabato et al. 2009; Vivier et al. 2010). The role of climate modes in the observed variability at the moorings is discussed further in section 4.

At the SOFS mooring, there are wintertime data for 2015 and 2017 (for the overlap time period only). The 

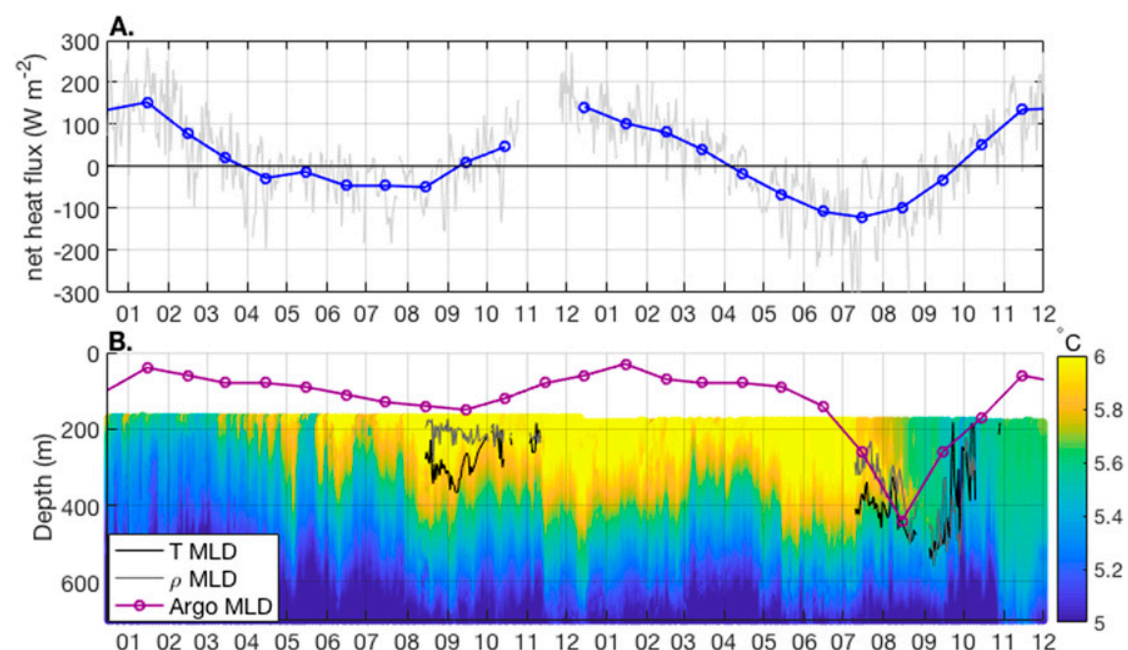
c.
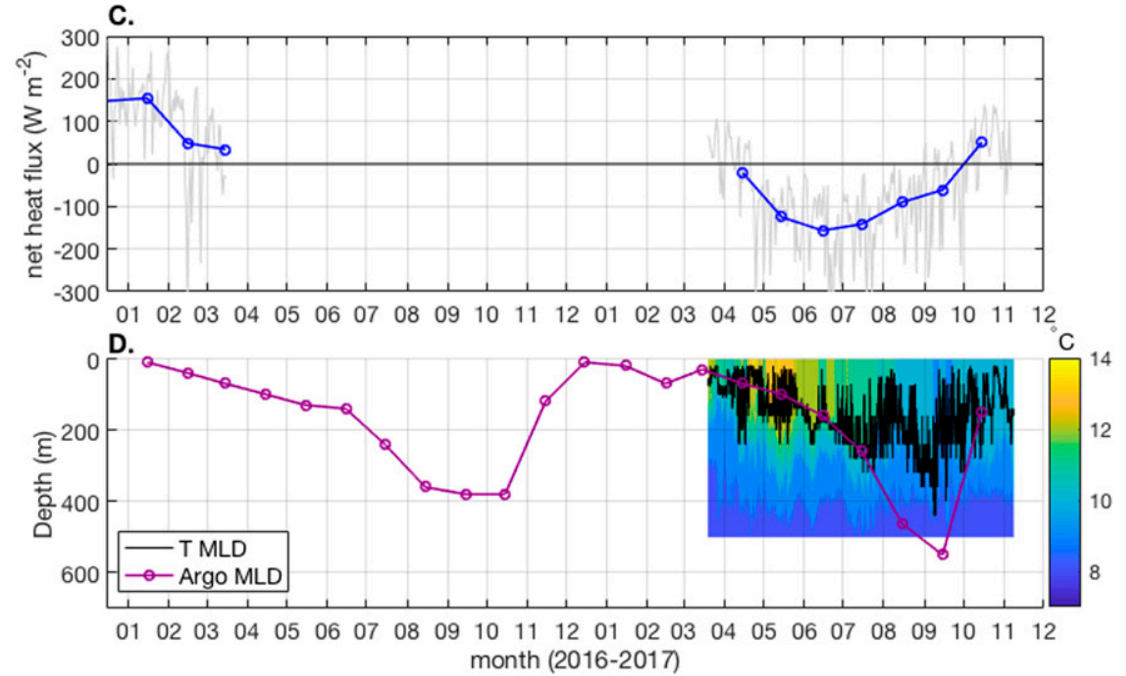

FIG. 7. Time series of (a) OOI mooring net heat flux daily values (gray line) and monthly means (blue circles and line) and (b) OOI subsurface temperature (Conservative Temperature) from the profiler mooring (color) and mixed layer depths (black line using a temperature threshold, gray line using a density threshold); (c) as in (a), but for the SOFS mooring, and (d) as in (b), but from fixed-depth temperature sensors on the SOFS mooring, with MLD using a temperature threshold only (black line). Purple circles and lines in (b) and (c) show monthly mean MLD at the closest grid point to each mooring location using a density threshold from the gridded Argo product (Roemmich and Gilson 2009). Note that mixed layer depths at the OOI mooring are only shown when there is sufficient near-surface CTD data from the flanking moorings and the mixed layer depth is deeper than $180 \mathrm{~m}$, the shallow extent of the profiler mooring (Ogle et al. 2018).

SOFS wintertime (JJA) mean net ocean heat loss is $94 \mathrm{~W} \mathrm{~m}^{-2}$ in 2015 and $129 \mathrm{~W} \mathrm{~m}^{-2}$ in 2017 (Fig. 8b). The ERA5 reanalyses had wintertime mean heat loss at the SOFS mooring location of $38 \mathrm{~W} \mathrm{~m}^{-2}$ in 2015 , and $58 \mathrm{~W} \mathrm{~m}^{-2}$ in 2017. In this case ERA5 significantly underestimated the wintertime heat loss, particularly in 2017, which is the opposite of the OOI mooring where the reanalyses typically overestimate heat loss. For the full time period of SOFS measurements (2010-18), the average difference between monthly mean net heat flux at the SOFS mooring and from ERA5 is $-29 \mathrm{Wm}^{-3}$ (meaning stronger heat loss measured by the SOFS mooring or equivalently more positive ERA5 heat fluxes), which indicates that this bias toward weaker heat loss at the SOFS mooring location is persistent in ERA5.

The SOFS 2015 and 2017 winter means are a similar magnitude to the OOI 2017 winter mean, but much stronger than the OOI 2016 mean, which supports the hypothesis that 2016 was marked by notably weak 

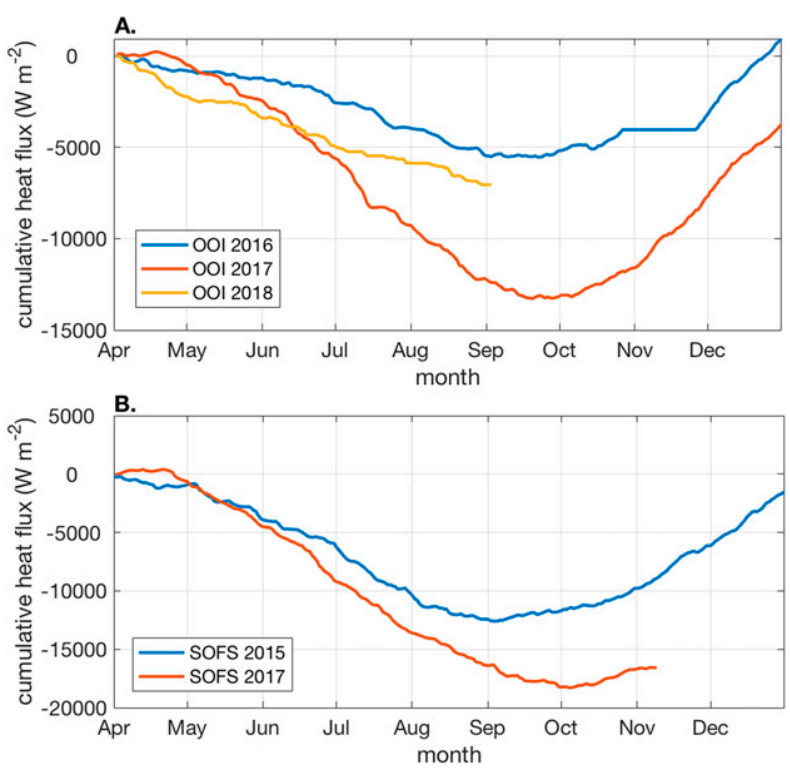

FIG. 8. Cumulative daily mooring mean net ocean heat loss from 1 April onward for each year between 2015 and May 2018 with sufficient mooring data for the (a) OOI mooring and (b) SOFS mooring.

wintertime heat loss at the OOI mooring in the SE Pacific (Ogle et al. 2018). The cumulative heat flux from 1 April onward (typically when the net heat flux transitions from net ocean heat gain to heat loss, Fig. 8) illustrates the strong year-to-year variation in wintertime heat loss, particularly at the OOI mooring. There yearto-year differences in the timing of transition to net ocean heat loss (March, April, May) and the transition to ocean heat gain (September, October) suggest that it may be more useful to consider cumulative fluxes rather than considering averages over a fixed winter period (Fig. 8). Given the difficulty of interpreting these wintertime differences in the short mooring time series, we extend out analysis to a longer time series from reanalysis to investigate interannual variability at the two mooring locations in the following section.

\section{b. Temporal and spatial context}

Interannual variability of heat flux and mixed layer depth at the two mooring locations is examined using longer time series, and also looking at patterns in heat fluxes and MLDs over the entire Southern Ocean region south of $30^{\circ} \mathrm{S}$ to provide a broader spatial context for the point mooring observations. We use monthly mean heat fluxes from the ERA5 reanalysis product (Copernicus Climate Change Service (C3S) 2017) and MLDs from a gridded Argo product (Roemmich and Gilson 2009). We consider the time period for which Argo data are available (2005-18) at the OOI and SOFS mooring sites and note this includes the full SOFS data-record (201017) (Fig. 9).

There is strong interannual variability in net heat flux and MLD at both moorings with stronger variability in both net heat flux and MLD in the wintertime (Fig. 9). There is reasonably good agreement between the observed monthly mean fluxes (heavy black lines and circles) and the ERA5 fluxes (thin black lines) (Fig. 9), with correlation coefficients (during months where mooring data are available) of 0.88 and 0.89 at the OOI and SOFS moorings, respectively $(p<0.01)$. However, there are some notable differences during the times when flux observations are available from both moorings. As identified in section 3a, the ERA5 wintertime heat loss is stronger than observed at the OOI mooring, particularly in 2016. The opposite is true at the SOFS mooring location, with weaker ERA5 wintertime heat loss than observed in some years, particularly 2015 and 2017. However, for times when there is no mooring data, it is not possible to determine biases in ERA5, so there may be additional errors in the interannual variability of the ERA5 fluxes that we are currently unable to quantify. These results clearly show that the ERA5 reanalysis fluxes have biases with respect to the mooring observations that are both spatially (i.e., between mooring sites) and temporally (i.e., between years) dependent. Thus, significant further research using longer mooring time series is required to understand the nature of these biases.

We estimate the annual cycle in net heat flux from ERA5 and MLD from the gridded Argo product (Roemmich and Gilson 2009) by calculating the mean and standard deviation for each month over the years 2005-17. As expected from Fig. 2, the annual cycle in net heat flux is very similar at the two moorings as it is dominated by the seasonal cycle in $Q_{\text {sw }}$ (Fig. 10a). Both mooring locations show a minimum net heat flux in June, and maximum in December, with an average difference between the mean monthly net flux at SOFS and OOI of $45 \mathrm{~W} \mathrm{~m}^{-2}$. The difference between the two moorings is somewhat larger during the spring months (SON), and there is no overlap in the standard deviations. As a result, the transition from net ocean heat loss to heat gain in the late austral winter or early austral spring typically occurs in mid-August at the SOFS mooring but not until mid- to late September at the OOI mooring in the ERA5 product. Observed monthly fluxes from the SOFS mooring for years 2010, 2012, 2015, and 2017 (overlaid in Fig. 10a as small blue circles and fine lines) indicate that this spring transition is observed to occur later at the SOFS mooring in these years than indicated by the 2005-17 ERA5 annual cycle, in late August through mid-September. This spring transition was only fully observed at the OOI mooring for years 2015 and 2017, but occurred at a similar time to 

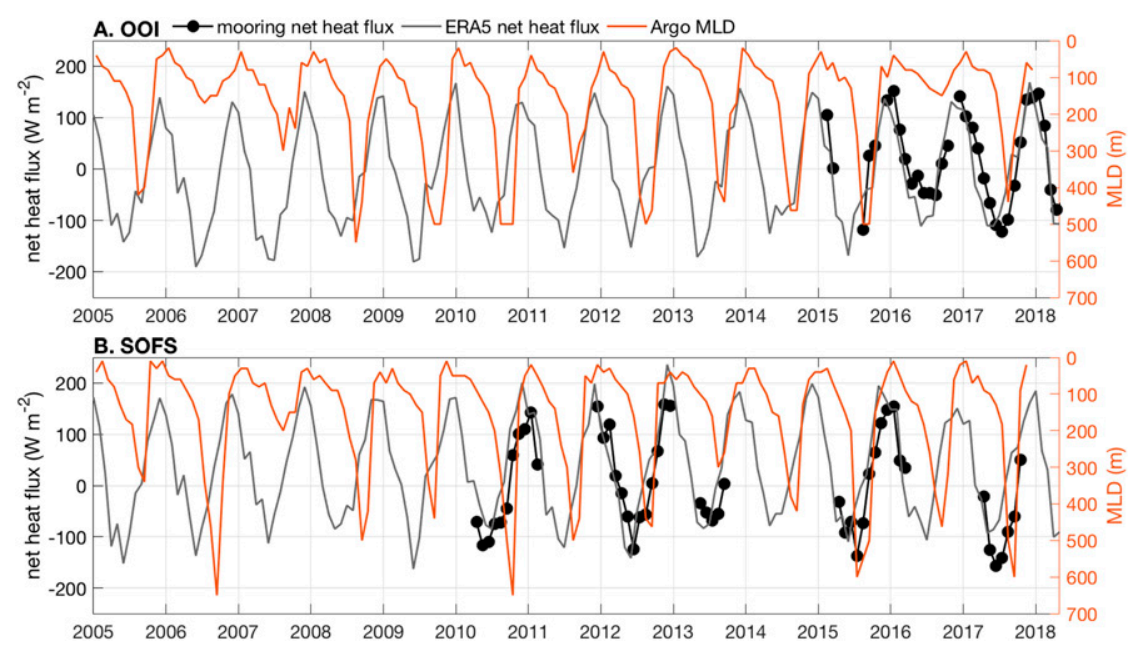

FIG. 9. Time series of monthly mean net air-sea heat flux observed at the mooring (black line and circles) and from the ERA5 reanalysis (gray line) and monthly mean mixed layer depths from a gridded Argo product (orange line) (Roemmich and Gilson 2009) at the (a) OOI and (b) SOFS mooring locations.

the SOFS mooring observations, and somewhat earlier than the ERA5 2005-17 mean.

The annual cycle in MLD is very similar at the two sites, with gradual mixed layer deepening starting in January, rapid deepening occurring from June onward to late winter, and rapid restratification occurring in October and November (Fig. 10b). Although the strongest wintertime ocean heat loss occurs in the same month at both mooring locations (Fig. 10a), on average the peak in wintertime MLD occurs in August at the OOI site and in September at the SOFS site (Fig. 10b). The large standard deviations at both moorings in August and September indicate that in any given year the timing of the MLD maximum may differ. We note that the MLDs based on the monthly mean gridded Argo product may have some errors in the timing of the MLD maxima as a result of uneven float sampling in space and time, particularly given the high-frequency variability in MLDs shown in the mooring data (Figs. 7b,d). Some years show an anomalously shallow winter MLD corresponding to weaker than average wintertime heat loss (e.g., 2016 at the OOI site, as observed by the mooring). However, in some other years there is no correspondence between the wintertime heat loss and resulting MLD (such as anomalously shallow MLDs at both the SOFS and OOI sites in 2007 when wintertime heat loss was fairly typical at both sites). The net heat flux is therefore not the only driver of interannual variations in MLD. For instance, Tamsitt et al. (2016) showed the importance of advective flux of heat in the upper $600 \mathrm{~m}$ of the Southern Ocean, while Cerovečki et al. (2019) showed the importance of advective flux of salt in the interannual variability of
SAMW volumes and associated MLD. However, further investigation into other mechanisms driving MLD variability at the moorings is beyond the scope of this analysis. We next examine the broader spatial structure of flux and MLD anomalies near the mooring locations.
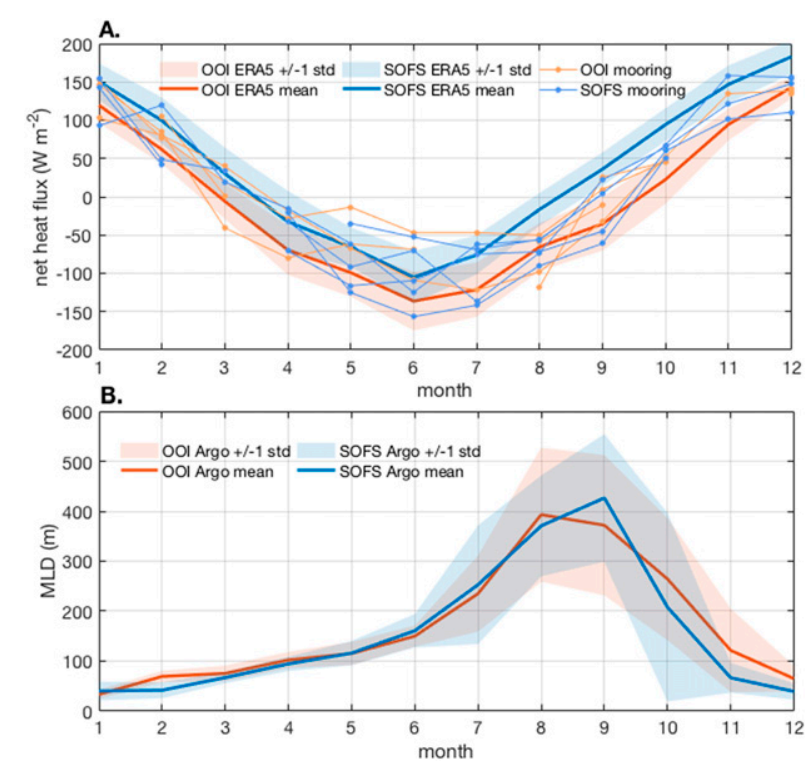

FIG. 10. The 2005-17 annual cycle in mean (solid line) and \pm 1 standard deviation (shading) at the OOI and SOFS mooring locations for (a) net heat flux from ERA5 monthly means and (b) mixed layer depth from Argo monthly mean gridded mixed layer depth. Thin lines and circles in (a) indicate monthly mean mooring observations for each year for 2015-17 for the OOI mooring (orange) and 2010-17 for the SOFS mooring (blue). 

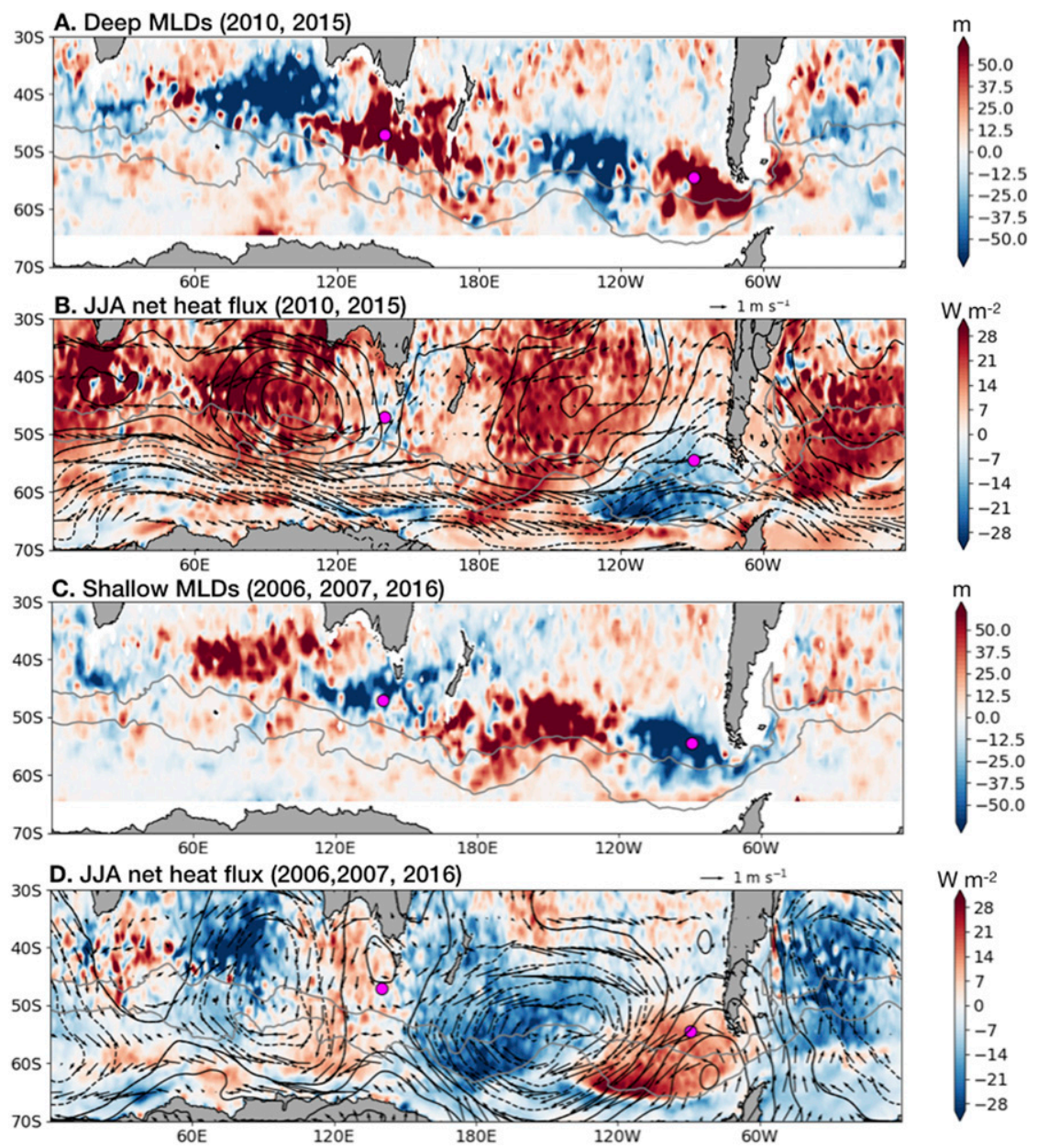

FIG. 11. Composites from ERA5 and gridded Argo of anomalously deep/shallow MLDs at the OOI site and corresponding wintertime flux anomalies. Argo gridded September mixed layer depth anomaly (relative to 2005-18 September mean) for (a) years with anomalously deep September mixed layer depth at the OOI mooring and surrounding region (2010 and 2015) and (c) years with anomalously shallow September mixed layer depth at the OOI mooring and surrounding region (2006, 2007, and 2016); wintertime (June, July, August) anomaly of net heat flux (colors, positive is anomalous ocean heat gain), surface pressure (black contours with intervals of $100 \mathrm{~Pa}$ with solid lines for positive anomalies and dashed lines for negative anomalies) and winds (arrows) for (b) years with anomalously deep September mixed layer depth at the OOI mooring and surrounding region (2010 and 2015) and (d) years with anomalously shallow September mixed layer depth at the OOI mooring and surrounding region $(2006,2007$, and 2016).

Using the 2005-17 typical annual cycle (as shown in Fig. 10), we calculate monthly mean anomalies in ERA5 and NCEP net heat flux and Argo MLD over the entire Southern Ocean south of $30^{\circ} \mathrm{S}$. We identify years when the MLD surrounding the OOI mooring is anomalously deep or shallow by finding Septembers when the average MLD anomaly in a $4^{\circ}$ latitude $\times 4^{\circ}$ longitude region centered on the OOI mooring exceeds $50 \mathrm{~m}$ above or below the 2005-18 September mean. Using these criteria, we create a composite map of wintertime net heat flux, winds, sea level pressure, and September MLD in anomalously deep mixed layer years at the OOI mooring site $(2010,2015)$ and anomalously shallow mixed layer years (2006, 2007, 2016) (Figs. 9 and 11). We note that the years included in the composites are not sensitive to the criteria definition (e.g., over a larger anomaly threshold or different sized region), and that the spatial pattern is similar for each individual year included in the composites, such that the composite pattern is not dominated by a single year. The MLD anomalies are also very similar in August and September of the same year, and thus are not sensitive to the month chosen. In 
both the deep and shallow MLD cases, there is a striking pattern of anomalies in MLD, with the same sign in MLD anomaly at the SOFS mooring location and at the OOI mooring location, and with MLD anomalies of the opposite sign to the west of each mooring. MLD anomalies in each of the years 2010 and 2015 look similar, with anomalously deep MLDs at both mooring locations, and anomalies are equal or more than one standard deviation above the mean MLD shown in Fig. $10 \mathrm{~b}$ at both moorings. In the shallow MLD case (2006, 2007, and 2016) MLDs are anomalously shallow at the OOI mooring and are more than one standard deviation below the mean MLD in all three years. At the SOFS mooring, in 2006 and 2016 the shallow MLD anomalies are weak (less than $50 \mathrm{~m}$ ), while in 2007 the MLD anomaly is large and move than one standard deviation below the SOFS mean MLD (Figs. 9 and 11).

In years when deep MLD anomalies develop in the eastern part of both the Pacific and Indian SAMW formation regions where moorings are located (years 2010, 2015), shallow MLD anomalies develop to the west of them, resulting in a dipole structure in both basins (Figs. 11a,c, Fig. S1). In the winters of 2010 and 2015 preceding anomalously deep mixed layers, zonal winds strengthened in the vicinity of the OOI mooring, while at the SOFS location there was increased transport from the southwest, advecting colder air (Fig. 11b, Fig. S1a). In both 2010 and 2015, the wintertime SAM was strong and positive in both 2010 and 2015, in agreement with strengthened zonal winds at the OOI location. In years when shallow MLD anomalies develop in the region surrounding the OOI mooring in the Pacific (2006, 2007, 2016), the composite MLD anomaly is much stronger at the OOI site than the SOFS site (Fig. 11c). While a strong shallow MLD anomaly that develops south of Australia, but the SOFS mooring is located on the edge of this region and the MLD anomaly is weak in 2006 and 2016 (less than $50 \mathrm{~m}$ ) but large in $2007(250 \mathrm{~m})$. In the region where the MLD shoals, there is strengthened southward transport of warm air, while in the region where the MLD deepens, northward transport of cold air strengthens (Fig. 11d, Fig. S1b).

The pattern of surface pressure anomalies in years with anomalously shallow MLDs in the southeast Pacific resembles a zonal wavenumber 3 (ZW3) pattern (Fig. 11d) (Raphael 2004; Schlosser et al. 2018). The pattern of surface pressure and surface heat flux anomalies shown in Fig. 11d was particularly strong in 2016, when despite the strong positive SAM index value during June, the MayJune average atmospheric circulation consisted of a ZW3 pattern (Clem et al. 2017). In autumn and winter of 2016, near-surface air temperature was anomalously high in the southeast Pacific, and anomalously low in the central
Pacific (Clem et al. 2017, their Fig. 6.3). At the SOFS mooring location near-surface air temperature was anomalously high in autumn but not in winter (Clem et al. 2017).

This result indicates that anomalous meridional atmospheric circulation associated with a circumpolar pressure anomaly with a ZW3 pattern, and the corresponding enhancement or weakening of wintertime ocean heat loss, plays a central role in the observed spatial pattern of MLD anomalies (Raphael 2004). Since deep wintertime MLDs at the two mooring locations feed the SAMW pools, we next calculate the water mass transformation and formation rates due to surface forcing in the SAMW density range following Walin (1982) (Fig. 12). This provides a link between interannual air-sea flux variability and variability in SAMW water mass formation. The surface transformation rate is the volume flux across a given density class due to airsea buoyancy forcing, integrated over the outcrop region of the density level, while the formation is the divergence of this quantity, representing the net rate of SAMW volume production due to air-sea fluxes of heat and freshwater (in Sverdrups). The goal of this calculation is to examine if years with anomalously deep and shallow MLDs in the vicinity of the OOI and SOFS moorings show qualitative agreement with anomalously strong and weak SAMW formation by air-sea buoyancy fluxes. We therefore only consider component of total SAMW formation due to surface buoyancy fluxes, and do not include the formation due to interior diabatic processes that contribute significantly to the total SAMW formation rate (e.g., Cerovečki and Mazloff 2016). Thus a complete quantitative analysis of the full SAMW formation rate including diapycnal mixing is beyond the scope of this work.

Figure 12 shows a time series of the surface formation rate of SAMW mode water in formation boxed regions defined in Fig. 12a: the central Indian, west of the SOFS mooring; the East Indian, which encompasses the SOFS mooring location; the central Pacific, which is west of the OOI mooring; and the southeast Pacific, which surrounds the OOI mooring location. These boxes are chosen to approximately capture the two dipole regions of SAMW formation in each basin as shown in Figs. 11a and $11 \mathrm{c}$. The formation rates due to surface fluxes only are estimated in each potential density bin $\left(0.02 \mathrm{~kg} \mathrm{~m}^{-3}\right.$ wide) in each of these regions in the wintertime of each year from 2005 to 2018 (Figs. 12b-e). Formation rates from the same region using ERA5 binned by neutral density (Fig. S2) and the same calculation repeated using NCEP for both potential density (Fig. S3) and neutral density (Fig. S4) show reasonably good qualitative agreement although the NCEP formation rates are 

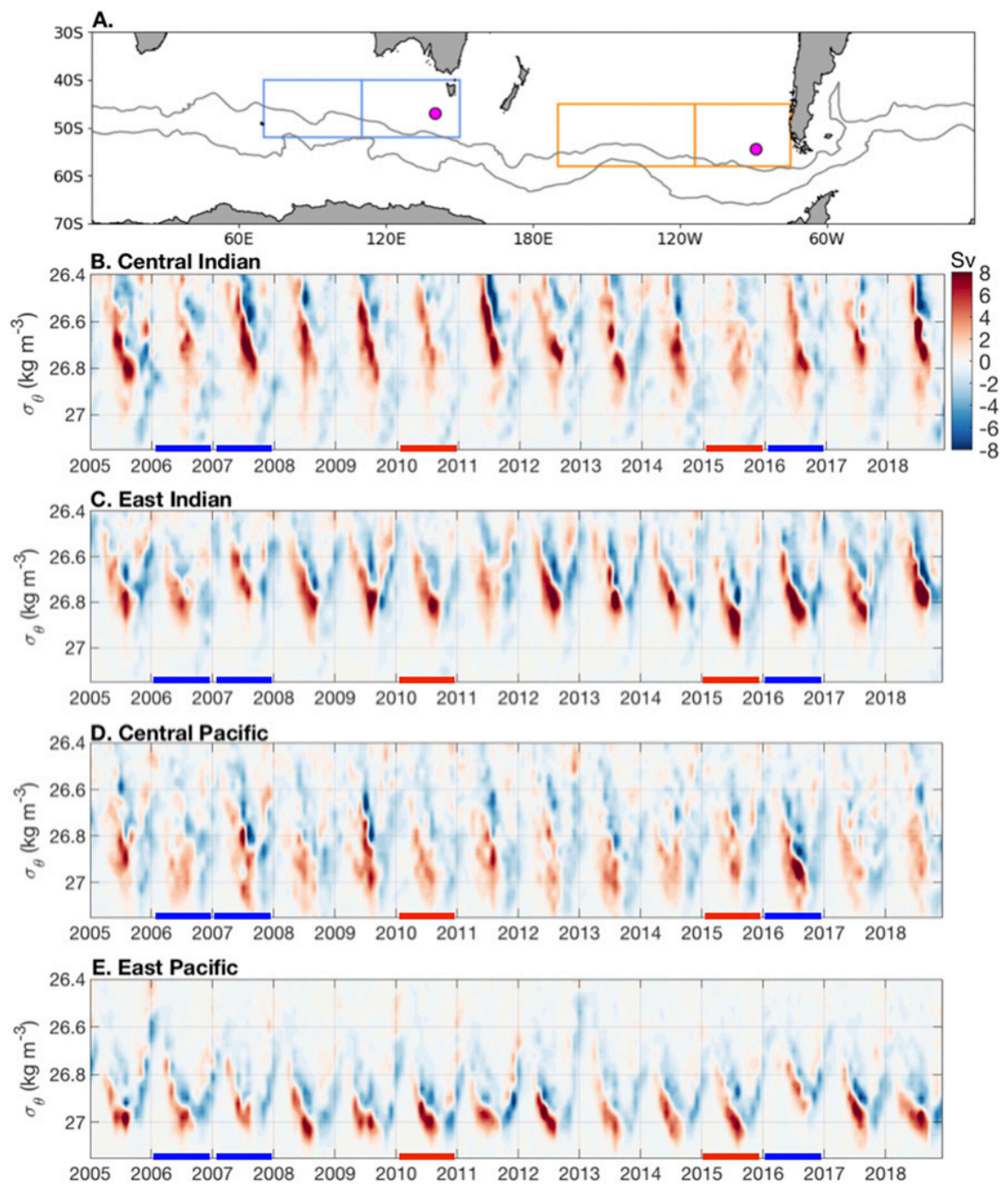

FIG. 12. Surface water mass formation of SAMW in the southeast Indian and southeast Pacific from ERA5 and Argo. (a) Map showing the four box regions used to spatially integrate surface water mass formation rates; time series of monthly mean water mass formation rate ( $\mathrm{Sv}$; positive is water mass formation) binned by potential density (referenced to the surface) for the (b) central Indian, (c) east Indian, (d) central Pacific, and (e) east Pacific. Red bars on the $x$ axis of (b)-(e) indicate years with anomalously deep MLDs and strong wintertime ocean heat loss at the OOI mooring shown in the composite in Figs. 11a and 11b, and blue bars indicate years with anomalously shallow MLDs and weak wintertime ocean heat loss at the OOI mooring (Figs. 11c,d).

substantially noisier than ERA5, which may be partly due to lower spatial resolution.

Each year, in each of the four regions, progressively denser SAMW is formed as the winter progresses, with destruction of lighter waters that are converted to SAMW via surface buoyancy loss (Fig. 12). In the Indian Ocean, winter surface formation typically occurs in the range $26.5 \leq \sigma \leq 26.85$ in the central Indian region, and $26.6 \leq \sigma \leq 26.95$ in the East Indian, although there is considerable interannual variation in the width and intensity of the formation peak. In the central Pacific, winter surface formation typically occurs in the range
$26.8 \leq \sigma \leq 27.0$, while in the eastern Pacific the wintertime formation is confined to a narrower density range $26.95 \leq \sigma \leq 27.15$ and tends to have a narrower, more intense peak than in the central Pacific.

In years with particularly strong MLD anomalies in the four regions, surface formation rate anomalies qualitatively agree with the wintertime anomalies in MLD and net heat flux, illustrating the close relationship between the surface SAMW formation and observed MLD variability (Figs. 11 and 12). In particular, in the winter of 2010 and 2015, there is strong formation of relatively dense SAMW in the east Indian (in the region surrounding the SOFS 
mooring), while the formation in the central Indian is weak in these years. Similarly, in 2010 and 2015, there is strong formation in the densest classes in the east Pacific, and weak formation in the central Pacific (Figs. 12b-e). This result is consistent with the anomalously strong/ weak wintertime ocean heat loss and deep/shallow MLDs in the central/east Indian and Pacific in these years (Figs. 11a,b). This suggests that the dipole in winter ocean heat loss resulting from anomalous atmospheric circulation directly impacts regional SAMW formation rates, leading to formation in different density classes, which may be masked when integrating formation rates over the entire Indian and Pacific regions.

A particularly striking example is 2016, when the winter SAMW formation is very weak and occurs in a lighter density range than is typical in the east Pacific region. This is consistent with the weak wintertime heat loss and shallow MLDs in the southeast Pacific surrounding the OOI mooring in this year (Figs. 1b, 8a, and $11 \mathrm{c}, \mathrm{d})$. In contrast, the surface formation in the central Pacific region is anomalously strong in 2016. Therefore the total Pacific SAMW formation was fairly typical in this year despite strong anomalies of opposite sign in SAMW formation in both the central and east Pacific SAMW formation regions. The other years with anomalously weak wintertime heat loss and shallow MLDs at the OOI mooring (2006 and 2007) show somewhat weaker formation in the east Pacific, but no strong anomalies in the central Pacific. Therefore the surface formation estimates confirm that the very weak wintertime heat loss observed at the OOI mooring in 2016 (Fig. 8a) leads to greatly reduced SAMW formation in the east Pacific region surrounding the OOI mooring. In the years with reduced heat loss in the region surrounding both the OOI and SOFS moorings $(2006,2007,2016)$ there is no clear pattern in the SAMW surface formation rates in the central and east Indian Ocean (Figs. 12b,c), similar to the lack of clear spatial pattern in MLD anomalies in the Indian Ocean in these years (Fig. 11c). Thus the interannual variability in MLD and SAMW formation appears to show a more consistent dipole pattern at the OOI mooring location than at the SOFS mooring location, particularly for years with weak wintertime heat loss.

\section{Discussion and conclusions}

This work provides the first comparison of simultaneous air-sea heat flux observations from two Southern Ocean moorings: one located in the southeast Indian sector (SOFS) and the second in the southeast Pacific sector (OOI). Although both moorings are located in regions with strong SAMW formation, north of the SAF, the observations reveal notable differences in the heat flux distributions and characteristics of heat loss events, which provide insight into differences in the drivers of interannual variability in SAMW formation. Both mooring sites experience a higher frequency in heat loss events in the austral autumn and winter, but the magnitude of heat loss events is stronger in the southeast Indian (SOFS) than the southeast Pacific (OOI). There is large interannual variability in both the wintertime net heat flux and MLD at both locations.

The interannual variability of SAMW formation rates and volume is not zonally uniform, but rather shows a large-scale dipole associated with atmospheric surface pressure and meridional wind anomalies in the south Indian and South Pacific. The same pattern is evident in the SAMW formation rates, with weak formation in the central and strong formation in the eastern part of both ocean sectors. In years when MLDs are anomalously deep in both the eastern south Indian and southeast Pacific Oceans (i.e., the locations of the two moorings), wintertime ocean heat loss shows a strong zonal dipole pattern in both sectors.

One interesting result is the presence of turbulent heat loss events associated with two different atmospheric regimes at the SOFS mooring, while heat loss events at the OOI mooring are dominated by a single regime. This is different from Schulz et al. (2012), who found turbulent heat loss events were associated with cold air flowing north in the first year of observations from the SOFS mooring, similar to what was found in the first analysis of the OOI mooring by Ogle et al. (2018). The extended time series from the SOFS site and the comparison with the OOI mooring have allowed us to identify this interesting difference in the characteristics of heat loss events. This indicates that the prevailing atmospheric patterns associated with the proximity of the southeast Indian SAMW formation region to the Australian continent lead to frequent strong latent heat loss events when drier air is advected over the region from the northwest, whereas in the southeast Pacific warm, moist, oceanic air from the northwest rarely leads to ocean heat loss. This result has implications for the role of episodic heat loss in mixed layer deepening and SAMW formation on longer time scales, as the two heat loss regimes at SOFS may respond differently to climate variability. This should be considered in future work that compares the role of surface forcing in SAMW formation in the southeast Indian and southeast Pacific regions.

Our analysis indicates that mooring measurements are key to efforts to continue to reduce biases in reanalysis products. The comparison of net heat flux with ERA5 indicates that there can be large offsets between the observed fluxes and the reanalyses, with offsets 
dependent both on location and the year under consideration. The reanalysis shows some agreement in the year-to-year variability in wintertime ocean heat loss, particularly at the OOI mooring but the offsets remain a source of concern. However, offsets in reanalysis fluxes can lead to a full month difference in the timing of the transition between ocean heat loss and ocean heat gain, which has significant implications for the timing of mixed layer deepening and restratification (Fig. 10). An in-depth, systematic comparison of reanalyses and the mooring observations will require more years of data than were available for the analysis reported here.

The concurrent, high temporal frequency air-sea flux and subsurface ocean temperature and salinity data at the moorings provide a unique insight into the role of air-sea fluxes in mixed layer evolution. Our results indicate differences in the relationship between air-sea heat flux and MLD at the two moorings (Figs. 7 and 9). Additional work is needed to quantify the relative role of air-sea fluxes and other processes in driving changes in MLD and mixed layer properties at these two locations. In particular, preconditioning likely plays a role in the response of mixed layers to wintertime ocean heat loss, and a mixed layer heat budget analysis or simple onedimensional mixed layer model [e.g., the model used by Holte et al. (2012)] would yield further insight on this topic.

ERA5 data for 2005-18 show large interannual variability in wintertime heat fluxes and corresponding SAMW formation rates and indicate that the period with overlapping mooring data (2015-17) was characterized by one of the strongest anomalies at both mooring locations. Particularly strong heat loss occurred in winter 2015 at both sites, while anomalously weak heat loss was observed in 2016 in the OOI mooring region. An interesting result is that winters with anomalously strong (and to a lesser extent weak) heat loss in the southeast Pacific typically show a similar anomaly in the southeast Indian, and associated anomalies in MLD reflect these anomalous heat fluxes. These anomalies are part of a broader dipole pattern characterized by positive and negative anomalies in both the Pacific and Indian basins.

The dipole in distribution has previously been tied to the SAM (Sen Gupta and England 2006; Sallée et al. 2010). Recent analysis of this dipole in the southeast Pacific from Argo data shows that the dipole in MLD is reflected in SAMW layer thickness, and is driven by the relative strength and sign of the large-scale SAM and ENSO atmospheric modes (Meijers et al. 2019). We show that this pattern can be related to the circumpolar surface pressure anomaly that has the ZW3 pattern (Raphael 2004), with MLD anomalies developing on the eastern and western flank of a strong surface pressure anomaly. As this pressure anomaly is associated with meridional wind anomalies of opposite signs on the western and eastern flank, this indicates that meridional atmospheric circulation plays a key role in the observed MLD anomalies. This pattern is particularly clear in the 2016 air-sea fluxes and MLDs, which coincide with an unusually strong ZW3 pattern that has been associated with the record minimum in Antarctic sea ice concentration in 2016 (Schlosser et al. 2018). ENSO has a particularly strong teleconnection to the atmospheric circulation and surface ocean conditions (e.g., Turner 2004; Fogt and Bromwich 2006) and a large impact on SAMW formation (Meijers et al. 2019) in the southeast Pacific, but not in the southeast Indian Ocean, which underscores the importance of considering interannual variability in SAMW formation regions individually. We note that variations in the frequency of extreme heat loss events discussed in section $3 \mathrm{a}$ also contribute to the interannual variability in wintertime ocean heat loss. These extreme heat loss events are often associated with cold air outbreaks associated with extratropical cyclones, and therefore influenced by the strength of the Southern Hemisphere storm track (Papritz et al. 2015), which in turn is affected by large-scale atmospheric modes including SAM and ENSO (Bracegirdle and Kolstad 2010; Ashok et al. 2007). Further work is needed to understand the drivers and contribution of extreme heat loss event frequency to interannual variability in wintertime ocean heat loss and corresponding SAMW formation.

To conclude, our results have implications for future efforts to sustain observations of air-sea fluxes in the Southern Ocean. The large year-to-year variability in mooring measurements and the presence of strong zonal asymmetry supports the need for longer time series at more than one location to accurately capture the "mean" annual cycle in different regions of the Southern Ocean. Wintertime measurements are of particular importance, as there is larger variability in wintertime net heat flux and MLD in winter than in summer (Fig. 10). Additionally, our analysis shows that while the variability measured at the two moorings is representative of the local SAMW pool, there is a large zonal asymmetry in wintertime net heat flux such that they are not representative of the entire southeast Indian and southeast Pacific SAMW formation regions. This suggests that greater spatial coverage of observations is necessary to resolve the zonal variability in this region of the Southern Ocean and would provide invaluable information toward understanding governing mechanisms of SAMW variability.

Acknowledgments. CSHOR is a joint research Centre for Southern Hemisphere Ocean Research between 
QNLM and CSIRO. IC was supported by the National Science Foundation (NSF) Ocean Sciences Grant NSF OCE-1658001 to Scripps Institution of Oceanography. SAJ is supported by the U.K. Natural Environment Research Council, including the ORCHESTRA Grant (NE/N018095/1). STG was supported by the U.S. National Science Foundation under Grants OCE-1658001 and PLR-1425989. OOI flux data can be obtained from the NSF Ocean Observatories Initiative Data Portal (http:// ooinet.oceanobservatories.org), and SOFS flux data can be obtained from the IMOS (Integrated Marine Observing System) Australian Ocean Data Network portal (https:// portal.aodn.org.au). The objectively mapped Argo data were provided by John Gilson, available from http:// www.argo.ucsd.edu/Gridded_fields.html. Argo data were collected and made freely available by the International Argo Program and the national programs that contribute to it (http://www.argo.ucsd.edu; http://argo.jcommops.org; http://doi.org/10.17882/42182). The Argo Program is part of the Global Ocean Observing System. The ERA5 dataset, developed by the European Centre for MediumRange Weather Forecasts, was obtained from the Research Data Archive at the National Center for Atmospheric Research, Computational and Information Systems Laboratory. VT would like to thank Matthew England, Annie Foppert, and Steve Rintoul for helpful discussions and feedback on the manuscript. We thank Sjoerd Groeskamp, Marcel du Plessis, and two anonymous reviewers for their feedback that has improved this manuscript.

\section{REFERENCES}

Ashok, K., H. Nakamura, and T. Yamagata, 2007: Impacts of ENSO and Indian Ocean dipole events on the Southern Hemisphere storm-track activity during austral winter. J. Climate, 20, 3147-3163, https://doi.org/10.1175/JCLI4155.1.

Bigorre, S. P., R. A. Weller, J. B. Edson, and J. D. Ware, 2013: A surface mooring for air-sea interaction research in the Gulf Stream. Part II: Analysis of the observations and their accuracies. J. Atmos. Oceanic Technol., 30, 450-469, https:// doi.org/10.1175/JTECH-D-12-00078.1.

Bracegirdle, T. J., and E. W. Kolstad, 2010: Climatology and variability of Southern Hemisphere marine cold-air outbreaks. Tellus, 62A, 202-208, https://doi.org/10.1111/j.1600-0870. 2009.00431.x.

Buongiorno Nardelli, B., S. Guinehut, N. Verbrugge, Y. Cotroneo, E. Zambianchi, and D. Iudicone, 2017: Southern Ocean mixed-layer seasonal and interannual variations from combined satellite and in situ data. J. Geophys. Res. Oceans, 122, 10 042-10 060, https://doi.org/10.1002/2017JC013314.

Cerovečki, I., and M. R. Mazloff, 2016: The spatiotemporal structure of diabatic processes governing the evolution of Subantarctic mode water in the Southern Ocean. J. Phys. Oceanogr., 46, 683710, https://doi.org/10.1175/JPO-D-14-0243.1.

— A. J. Meijers, M. R. Mazloff, S. T. Gille, V. M. Tamsitt, and P. R. Holland, 2019: The effects of enhanced sea ice export from the Ross Sea on recent cooling and freshening of the southeast Pacific. J. Climate, 32, 2013-2035, https://doi.org/ 10.1175/JCLI-D-18-0205.1.

Clem, K. E., S. Barreira, and R. L. Fogt, 2017: Atmospheric circulation [in "State of the Climate in 2016"]. Bull. Amer. Meteor. Soc., 98 (8), S35-S41.

Close, S. E., A. C. Naveira Garabato, E. L. McDonagh, B. A. King, M. Biuw, and L. Boehme, 2013: Control of mode and intermediate water mass properties in Drake Passage by the Amundsen Sea low. J. Climate, 26, 5102-5123, https://doi.org/ 10.1175/JCLI-D-12-00346.1.

Colbo, K., and R. A. Weller, 2009: Accuracy of the IMET sensor package in the subtropics. J. Atmos. Oceanic Technol., 26, 1867-1890, https://doi.org/10.1175/2009JTECHO667.1.

Copernicus Climate Change Service (C3S), 2017: ERA5: Fifth generation of ECMWF atmospheric reanalyses of the global climate. Copernicus Climate Change Service Climate Data Store (CDS), accessed 18 March 2019, https://cds.climate. copernicus.eu/cdsapp\#!/home.

de Boyer Montégut, C., G. Madec, A. S. Fischer, A. Lazar, and D. Iudicone, 2004: Mixed layer depth over the Global Ocean: An examination of profile data and a profile-based climatology. J. Geophys. Res., 109, C12003, https://doi.org/10.1029/ 2004JC002378.

Edson, J. B., and Coauthors, 2013: On the exchange of momentum over the open ocean. J. Phys. Oceanogr., 43, 1589-1610, https://doi.org/10.1175/JPO-D-12-0173.1.

Fogt, R. L., and D. H. Bromwich, 2006: Decadal variability of the ENSO teleconnection to the high-latitude South Pacific governed by coupling with the southern annular mode. J. Climate, 19, 979-997, https://doi.org/10.1175/JCLI3671.1.

Groeskamp, S., S. M. Griffies, D. Iudicone, R. Marsh, A. G. Nurser, and J. D. Zika, 2019: The water mass transformation framework for ocean physics and biogeochemistry. Annu. Rev. Mar. Sci., 11, 271-305, https://doi.org/10.1146/annurev-marine-010318-095421.

Hanawa, K., and L. D. Talley, 2001: Mode waters. Ocean Circulation and Climate, G. Siedler et al., Eds., International Geophysics Series, Academic Press, 373-386.

Hartin, C. A., R. A. Fine, B. M. Sloyan, L. D. Talley, T. K. Chereskin, and J. Happell, 2011: Formation rates of Subantarctic mode water and Antarctic intermediate water within the South Pacific. Deep-Sea Res. I, 58, 524-534, https://doi.org/10.1016/ j.dsr.2011.02.010.

Holte, J., L. D. Talley, T. K. Chereskin, and B. M. Sloyan, 2012: The role of air-sea fluxes in Subantarctic Mode Water formation. J. Geophys. Res., 117, C03040, https://doi.org/10.1029/ $2011 \mathrm{jc} 007798$.

,-- , J. Gilson, and D. Roemmich, 2017: An Argo mixed layer climatology and database. Geophys. Res. Lett., 44, 56185626, https://doi.org/10.1002/2017GL073426.

Hosom, D. S., R. A. Weller, R. E. Payne, and K. E. Prada, 1995: The IMET (improved meteorology) ship and buoy systems. J. Atmos. Oceanic Technol., 12, 527-540, https://doi.org/ 10.1175/1520-0426(1995)012<0527:TIMSAB > 2.0.CO;2.

Hu, S., and A. V. Fedorov, 2017: The extreme El Niño of 2015-2016 and the end of global warming hiatus. Geophys. Res. Lett., 44, 3816-3824, https://doi.org/10.1002/2017GL072908.

Ito, T., M. Woloszyn, and M. Mazloff, 2010: Anthropogenic carbon dioxide transport in the Southern Ocean driven by Ekman flow. Nature, 463, 80-83, https://doi.org/10.1038/nature08687.

Iudicone, D., S. Speich, G. Madec, and B. Blanke, 2008: The global conveyor belt from a Southern Ocean perspective. J. Phys. Oceanogr., 38, 1401-1425, https://doi.org/10.1175/2007JPO3525.1. 
Jackett, D. R., and T. J. McDougall, 1997: A neutral density variable for the world's oceans. J. Phys. Oceanogr., 27, 237-263, https://doi.org/10.1175/1520-0485(1997)027<0237:ANDVFT> 2.0.CO;2.

Josey, S. A., M. F. de Jong, M. Oltmanns, G. Moore, and R. A. Weller, 2019: Extreme variability in Irminger Sea winter heat loss revealed by ocean observatories initiative mooring and the ERA5 reanalysis. Geophys. Res. Lett., 46, 293-302, https:// doi.org/10.1029/2018GL080956.

Kalnay, E., and Coauthors, 1996: The NCEP/NCAR 40-Year Reanalysis Project. Bull. Amer. Meteor. Soc., 77, 437-471, https://doi.org/10.1175/1520-0477(1996)077<0437:TNYRP> 2.0.CO;2.

Kwon, E. Y., 2013: Temporal variability of transformation, formation, and subduction rates of upper Southern Ocean waters. J. Geophys. Res. Oceans, 118, 6285-6302, https://doi.org/ 10.1002/2013JC008823.

Marshall, J., D. Jamous, and J. Nilsson, 1999: Reconciling thermodynamic and dynamic methods of computation of watermass transformation rates. Deep-Sea Res. I, 46, 545-572, https://doi.org/10.1016/S0967-0637(98)00082-X.

Maze, G., G. Forget, M. Buckley, J. Marshall, and I. Cerovecki, 2009: Using transformation and formation maps to study the role of air-sea heat fluxes in North Atlantic eighteen degree water formation. J. Phys. Oceanogr., 39, 1818-1835, https:// doi.org/10.1175/2009JPO3985.1.

McCartney, M., 1977: Subantarctic mode water. A Voyage of Discovery: George Deacon 70th Anniversary Volume, M. V. Angel, Ed., Pergamon Press, 103-119.

Meijers, A., I. Cerovečki, B. A. King, and V. Tamsitt, 2019: A seesaw in Pacific Subantarctic mode water formation driven by atmospheric modes. Geophys. Res. Lett., 46, 13152-13160, https://doi.org/10.1029/2019GL085280.

Naveira Garabato, A. C., L. Jullion, D. P. Stevens, K. J. Heywood, and B. A. King, 2009: Variability of Subantarctic Mode Water and Antarctic intermediate water in the Drake Passage during the late-twentieth and early-twenty-first centuries. J. Climate, 22, 3661-3688, https://doi.org/10.1175/2009JCLI2621.1.

Nurser, A., R. Marsh, and R. G. Williams, 1999: Diagnosing water mass formation from air-sea fluxes and surface mixing. J. Phys. Oceanogr., 29, 1468-1487, https://doi.org/10.1175/ 1520-0485(1999)029<1468:DWMFFA > 2.0.CO;2.

Ogle, S. E., V. Tamsitt, S. A. Josey, S. T. Gille, I. Cerovečki, L. D. Talley, and R. A. Weller, 2018: Episodic Southern Ocean heat loss and its mixed layer impacts revealed by the farthest south multiyear surface flux mooring. Geophys. Res. Lett., 45, 50025010, https://doi.org/10.1029/2017GL076909.

Orsi, A. H., T. Whitworth, and W. D. Nowlin, 1995: On the meridional extent and fronts of the Antarctic Circumpolar Current. Deep-Sea Res. I, 42, 641-673, https://doi.org/10.1016/ 0967-0637(95)00021-W.

Papritz, L., S. Pfahl, H. Sodemann, and H. Wernli, 2015: A climatology of cold air outbreaks and their impact on air-sea heat fluxes in the high-latitude South Pacific. J. Climate, 28, 342364, https://doi.org/10.1175/JCLI-D-14-00482.1.

Raphael, M. N., 2004: A zonal wave 3 index for the Southern Hemisphere. Geophys. Res. Lett., 31, L23212, https://doi.org/ 10.1029/2004GL020365.

Rintoul, S. R., and M. H. England, 2002: Ekman transport dominates local air-sea fluxes in driving variability of Subantarctic Mode Water. J. Phys. Oceanogr., 32, 1308-1321, https://doi.org/10.1175/1520-0485(2002)032<1308:ETDLAS > 2.0.CO;2.
Roemmich, D., and J. Gilson, 2009: The 2004-2008 mean and annual cycle of temperature, salinity, and steric height in the Global Ocean from the Argo program. Prog. Oceanogr., 82, 81-100, https://doi.org/10.1016/j.pocean.2009.03.004.

Sabine, C. L., and Coauthors, 2004: The oceanic sink for anthropogenic $\mathrm{CO}_{2}$. Science, 305, 367-371, https://doi.org/10.1126/ science.1097403.

Sallée, J., R. Morrow, and K. Speer, 2008: Eddy heat diffusion and Subantarctic Mode Water formation. Geophys. Res. Lett., 35, L05607, https://doi.org/10.1029/2007GL032827.

- K. Speer, and S. Rintoul, 2010: Zonally asymmetric response of the Southern Ocean mixed-layer depth to the Southern Annular Mode. Nat. Geosci., 3, 273-279, https://doi.org/10.1038/ngeo812.

Santoso, A., M. J. Mcphaden, and W. Cai, 2017: The defining characteristics of ENSO extremes and the strong 2015/2016 El Niño. Rev. Geophys., 55, 1079-1129, https://doi.org/10.1002/ 2017RG000560.

Schlosser, E., F. A. Haumann, and M. N. Raphael, 2018: Atmospheric influences on the anomalous 2016 Antarctic Sea ice decay. Cryosphere, 12, 1103-1119, https://doi.org/10.5194/ tc-12-1103-2018.

Schulz, E. W., S. A. Josey, and R. Verein, 2012: First air-sea flux mooring measurements in the Southern Ocean. Geophys. Res. Lett., 39, L16606, https://doi.org/10.1029/2012GL052290.

Sen Gupta, A., and M. H. England, 2006: Coupled oceanatmosphere-ice response to variations in the Southern Annular Mode. J. Climate, 19, 4457-4486, https://doi.org/ 10.1175/JCLI3843.1.

Sloyan, B. M., and S. R. Rintoul, 2001: Circulation, renewal, and modification of Antarctic mode and intermediate water. J. Phys. Oceanogr., 31, 1005-1030, https://doi.org/10.1175/ 1520-0485(2001)031<1005:CRAMOA > 2.0.CO;2.

L. D. Talley, T. K. Chereskin, R. Fine, and J. Holte, 2010: Antarctic intermediate water and Subantarctic Mode Water formation in the southeast Pacific: The role of turbulent mixing. J. Phys. Oceanogr., 40, 1558-1574, https://doi.org/10.1175/ 2010JPO4114.1.

Speer, K., and E. Tziperman, 1992: Rates of water mass formation in the North Atlantic Ocean. J. Phys. Oceanogr., 22, 93-104, https://doi.org/10.1175/1520-0485(1992)022<0093:ROWMFI> 2.0. $\mathrm{CO} ; 2$

Stuecker, M. F., C. M. Bitz, and K. C. Armour, 2017: Conditions leading to the unprecedented low Antarctic Sea ice extent during the 2016 austral spring season. Geophys. Res. Lett., 44, 9008-9019, https://doi.org/10.1002/2017GL074691.

Tamsitt, V., L. D. Talley, M. R. Mazloff, and I. Cerovečki, 2016: Zonal variations in the Southern Ocean heat budget. J. Climate, 29, 6563-6579, https://doi.org/10.1175/JCLI-D-15-0630.1.

Turner, J., 2004: The El Niño-southern oscillation and Antarctica. Int. J. Climatol., 24, 1-31, https://doi.org/10.1002/JOC.965.

Vivier, F., D. Iudicone, F. Busdraghi, and Y.-H. Park, 2010: Dynamics of sea-surface temperature anomalies in the Southern Ocean diagnosed from a 2D mixed-layer model. Climate Dyn., 34, 153-184, https://doi.org/10.1007/s00382-009-0724-3.

Walin, G., 1982: On the relation between sea-surface heat flow and thermal circulation in the ocean. Tellus, 34, 187-195, https:// doi.org/10.3402/tellusa.v34i2.10801.

Weller, R. A., S. P. Bigorre, J. Lord, J. D. Ware, and J. B. Edson, 2012: A surface mooring for air-sea interaction research in the Gulf Stream. Part I: Mooring design and instrumentation. J. Atmos. Oceanic Technol., 29, 1363-1376, https://doi.org/ 10.1175/JTECH-D-12-00060.1. 